\title{
استقراء النظم الرياضية فى فواتح السور القرآنية وتطبيقها فى مجال التصميمات الزخرفية

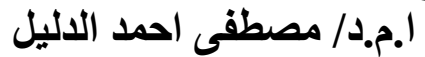

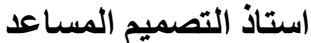 \\ كلية التربية النوعية - جامعة دمياط المباط
}

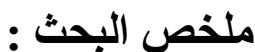

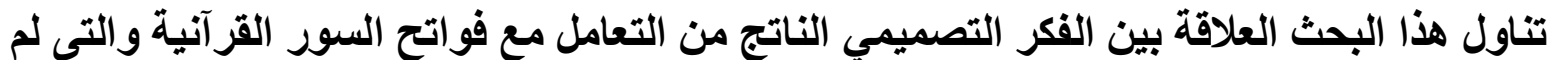

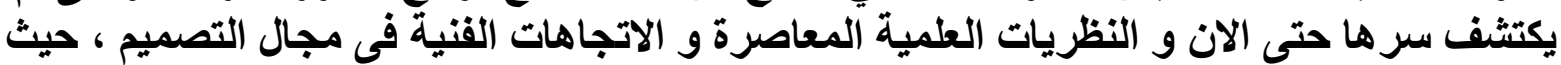

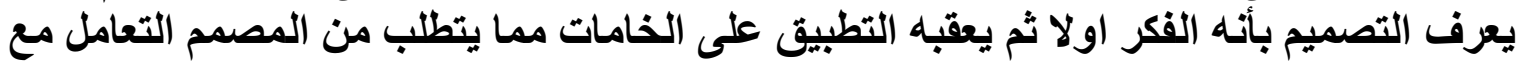

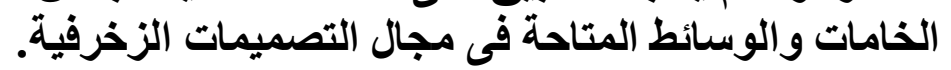

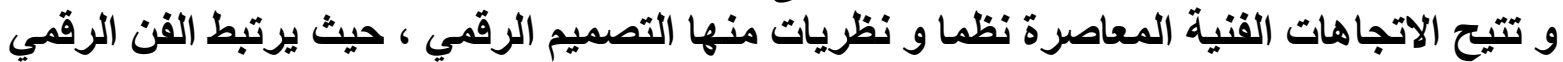

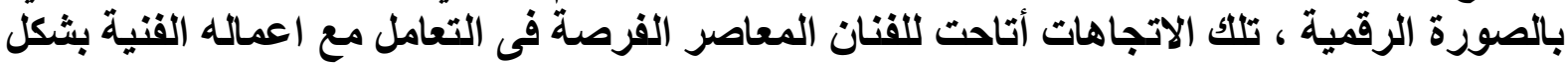

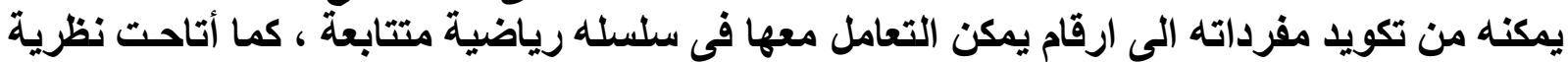

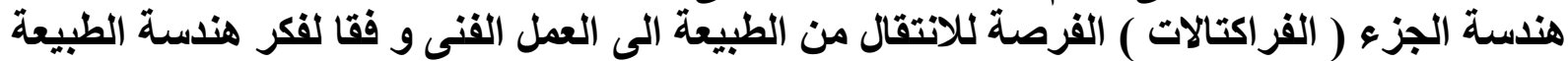

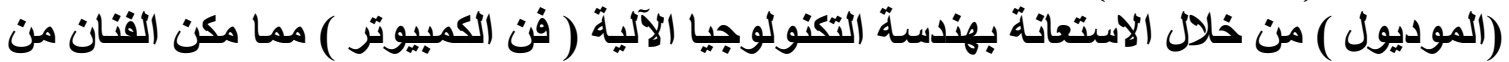

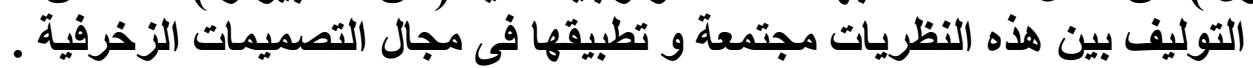

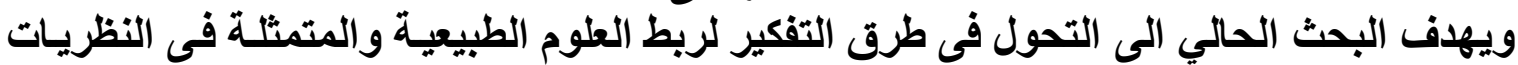

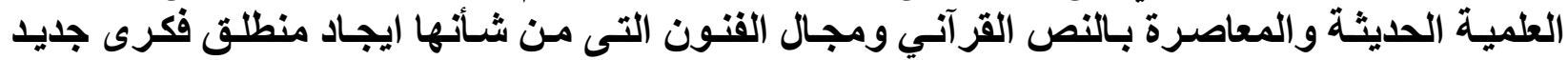

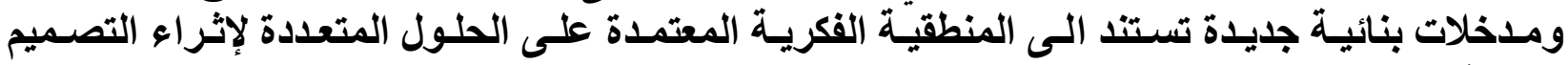
وتأتى اهمية البحث الحالى فى الكثف عن مزاوجة النظريات الهندسية الكسبرية وفواتح السور

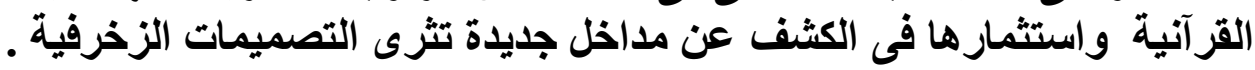

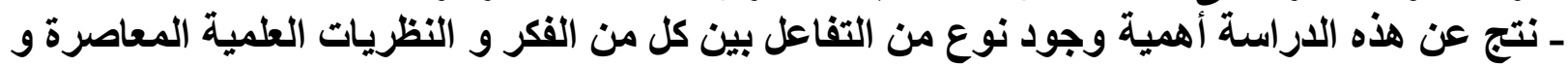

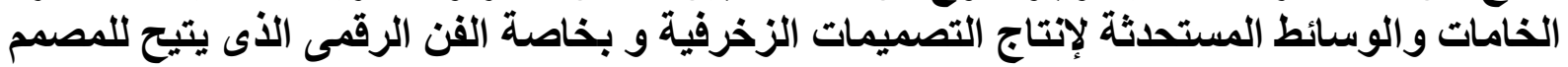

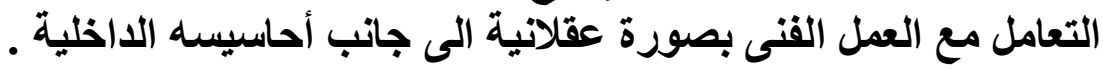

Extrapolation of systems mathematical the beginnings of the fence in the Koran and the application in the field of decorative designs Prof. Dr. / Mustafa Ahmed El dalil Assistant professor of design Faculty of Specific Education - Damietta University

Research Summary:

This research deals with the relationship between thought the design output of dealing with the beginnings of The beginnings of chapters which did not discover her secret until now, and and verses, the Koran theories of contemporary scientific and technical trends in the field of 
design, where it is known design that he thought first and then followed by the application on raw materials, which requires the designer to deal with the raw materials and the media available in the field of decorative designs. And allows contemporary art trends systems and theories, including Digital Design, where associated art digital image digital, these trends allowed the artist contemporary opportunity to deal with his art as he can from the coding vocabulary figures can be handled in a series of mathematical sequence, also allowed the theory of engineering segment (fraktal) the opportunity to move from the technical nature of the work and according to the nature of the thought of Engineering (module) through the use of automated engineering technology (computer art) which enabled the artist of synthesis between these theories combined and applied in the field of decorative designs.

The current research aims to shift in ways of thinking to connect the natural sciences and the scientific theories of modern and contemporary Quranic text and the arts, which will find out new intellectual input and new construction is based on the logical IP-based multiple solutions to enrich the decorative design.

The importance of the present research in the detection of pairing theories Fractal Geometry and the beginnings of The beginnings of chapters and and invested in the detection of new entries enrich verses, the Koran decorative designs.

- Resulted in this study, the importance of having some kind of interaction between each of the thought and scientific theories and contemporary materials and media developed for the production of decorative designs and especially digital art allows the designer to deal with the technical work rationally, along with feelings of Interior 


\section{استقراء النظم الرياضية فى فواتح السور القرآنية وتطبيقها فى مجال التصميمات الزخرفية

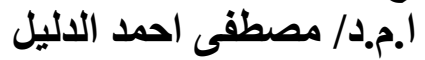

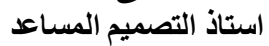 \\ كلية التربية النوعية - جامعة دمياط}

مقإمسـة

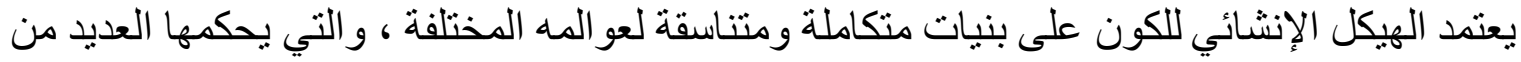

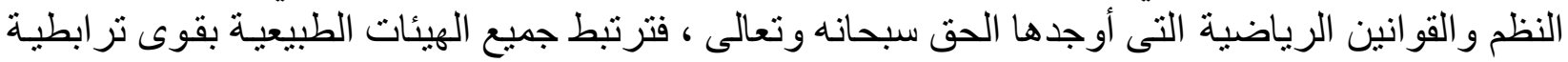

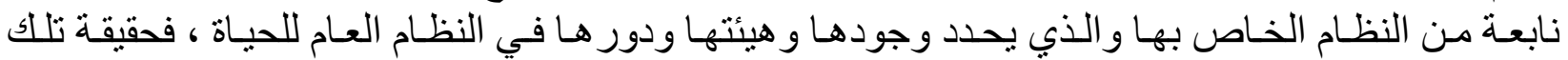

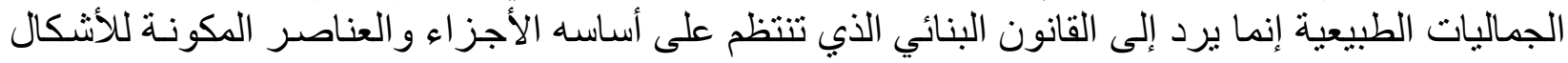
و الهيئات الطبيعية .

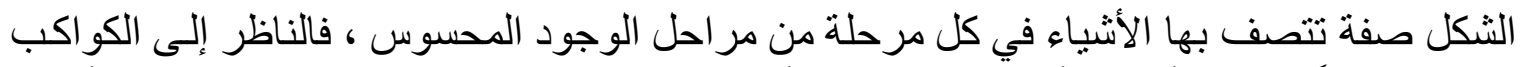

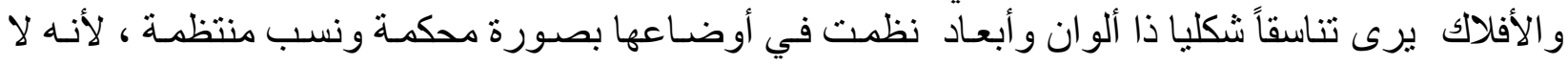

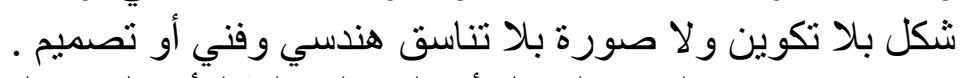

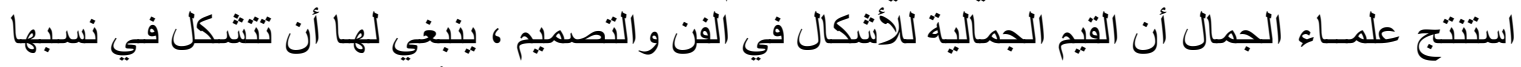

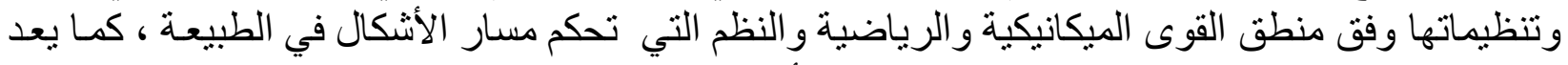

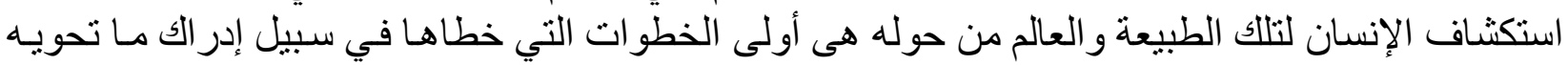

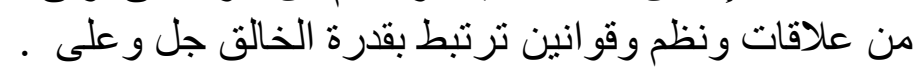

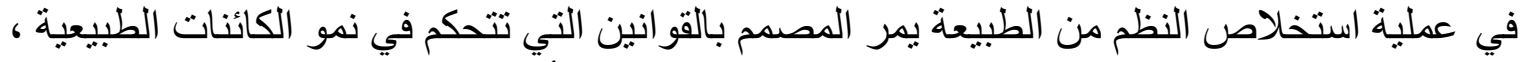

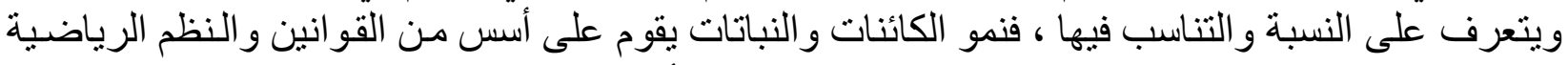

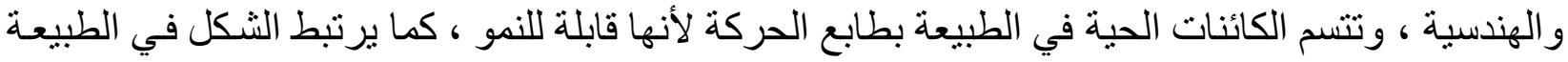

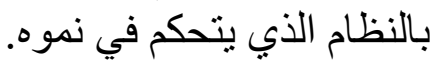
لقد تطورت الرياضيات بكل فرو عها من العيني إلى المجرد و من العن العيان التجريبي إلى التجريد

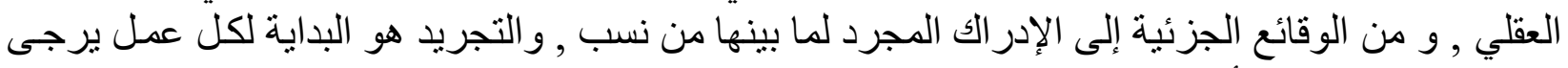

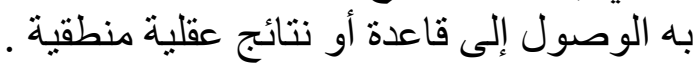

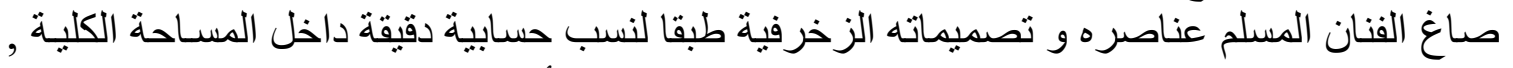

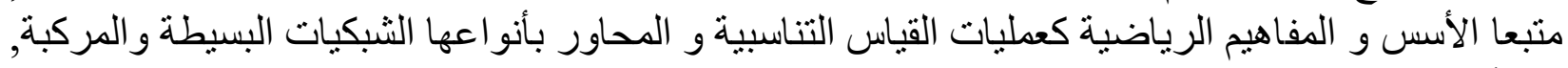

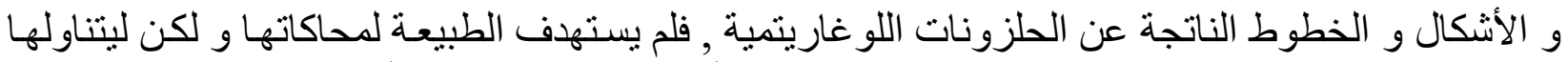

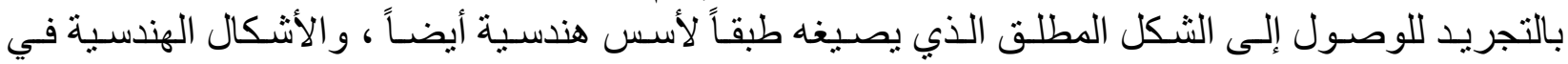

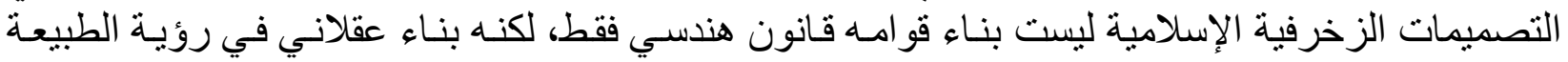

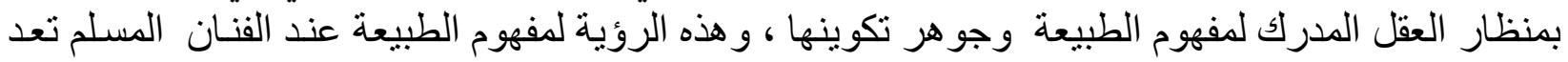

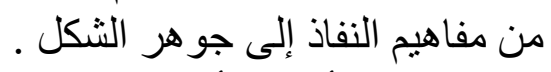

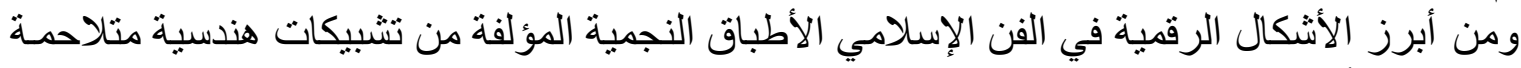

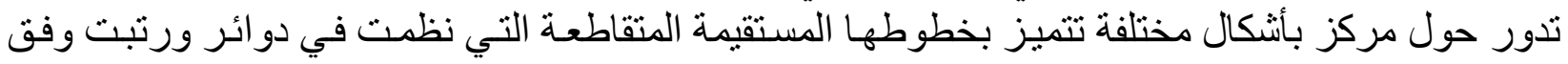

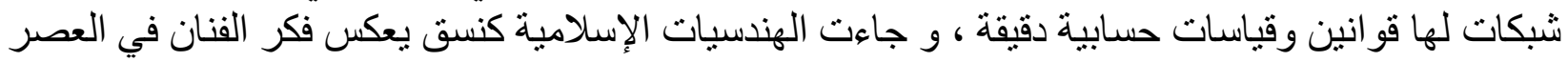

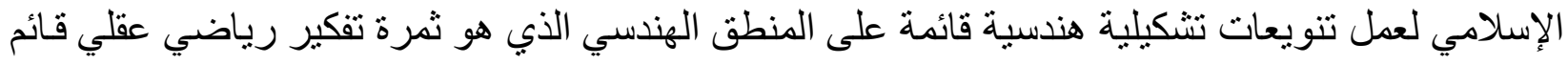

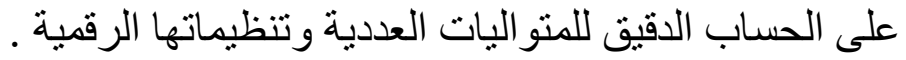




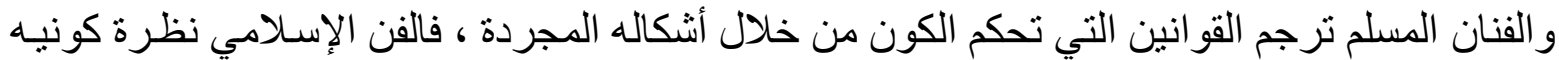

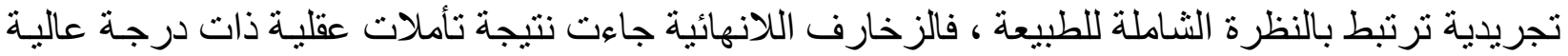

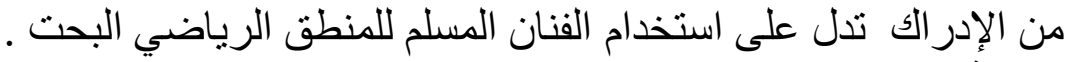

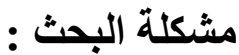

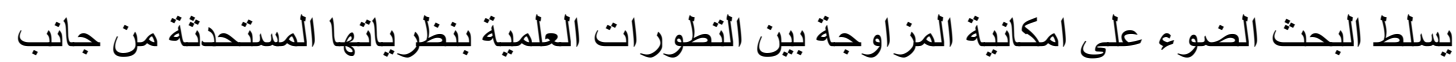

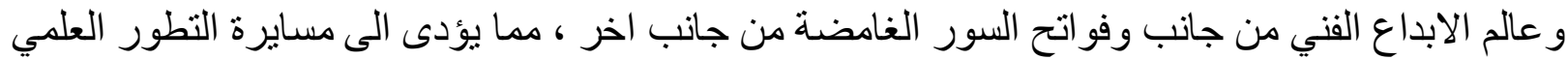

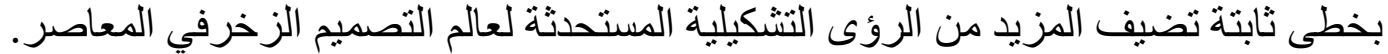

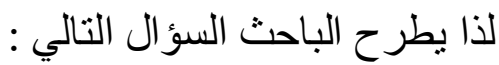
الى اى مدى يمكن استقر اءو وفهر و تحليل النظم البنائية الرياضية للهندسة الكسيرية فى فو اتح السور

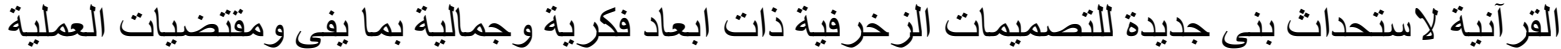

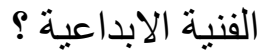

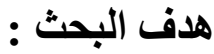

التحول فى طرق التفكير لربط العلوم الطبيعية والمتمثلة فى النظريات العلمية الحديثة و المعاصرة

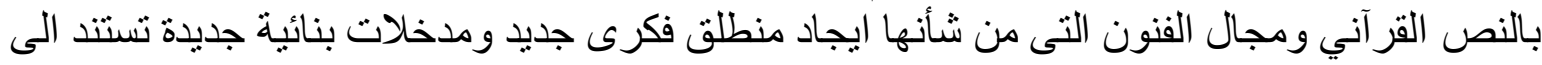

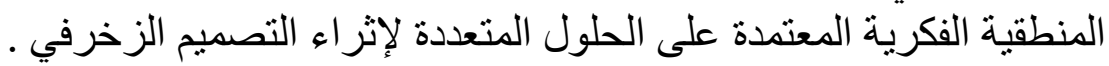
الكثف عن مزاوجة النظريات الهندية الكسيرية وفواتح السور القرآنية واستثمار ها فى الكثف عن

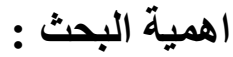
مداخل جديدة تثرى التصميمات الزخرفية .

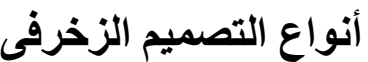

\begin{tabular}{|c|c|c|c|}
\hline \multicolumn{2}{|c|}{ من حيث المحتوى أو المضمون } & \multicolumn{2}{|c|}{ من حيث الثُكل أو الهيئة } \\
\hline مضمون & عناصر & مجسم & مسطح \\
\hline قيم مستمدة من العقيدة & عناصر التصميم & تجسيم جزئى & ذَى بعدين \\
\hline معانى مجردة & \multirow[t]{2}{*}{ مفردات تشكيلية } & \multirow[t]{2}{*}{ تجسيم كلى } & \multirow[t]{2}{*}{ ت تعدد الأبعاد } \\
\hline قيم جمالية مطلقة & & & \\
\hline
\end{tabular}

\section{Grids Geometrical الشبكات الهندسية}

هنالك علاقة ارتباط وثثقة بين التصميم و النظام الهندسي و الثبكات , حيث أن الثبكات التيكات الهندسية

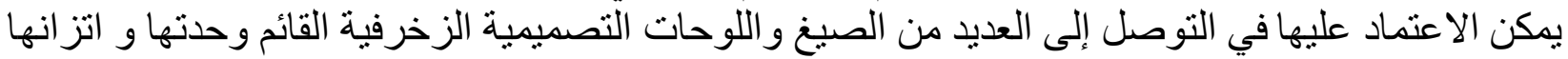

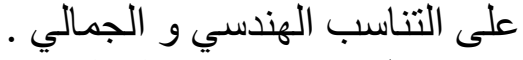

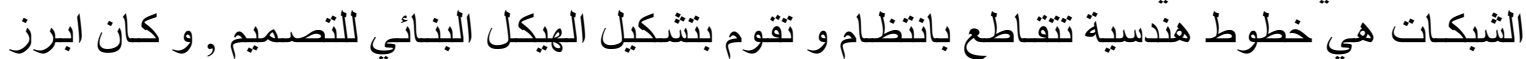

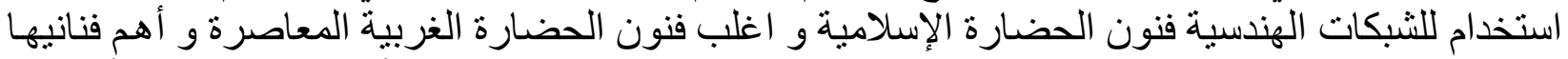

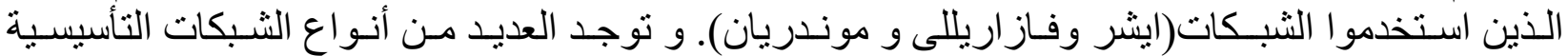

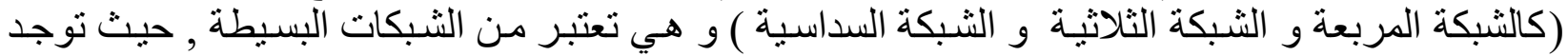
شبكات أخرى أكثر تعقيدا و هي شبكات مركبة من نوعين أو أكثر من الأنو اعثر المذكورة تتنج من تلاحم

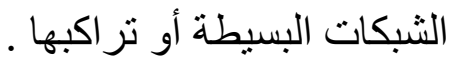
و الثبكات الهندية التأسيسية لها أهمية في عمليه التصميم من خلال ما يلي :

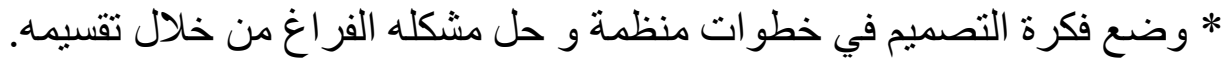
* إنماء التصميم كعملية تركيبية من خلال الحذف و و الإضافة في أشكال الثبكة. * إيجاد إيقاعات ديناميكية متكررة . 
* الحصـول على تصميمات تتسم بالاستمر ارية اللانهائية تتميز بالحركة و التكرار و الوحدة و التنوع و الإيقاع و التبادل بين الثكل و الأرضية.

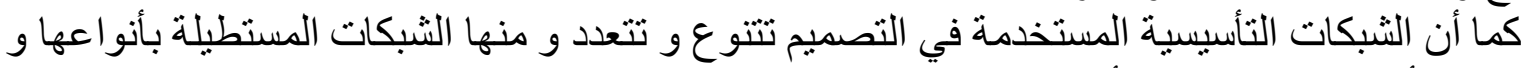

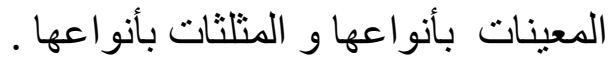

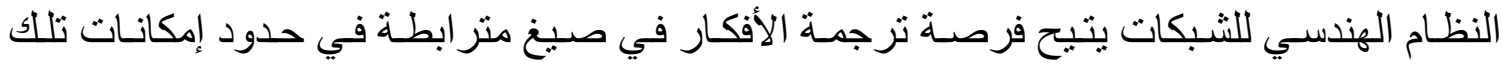

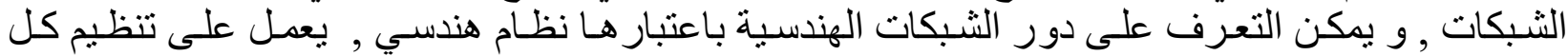

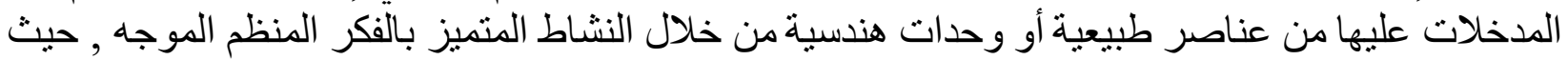

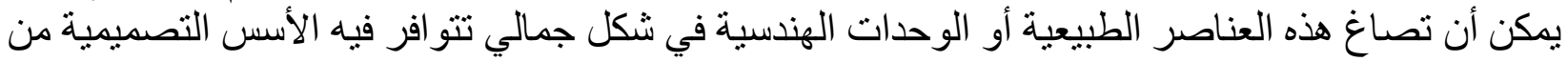

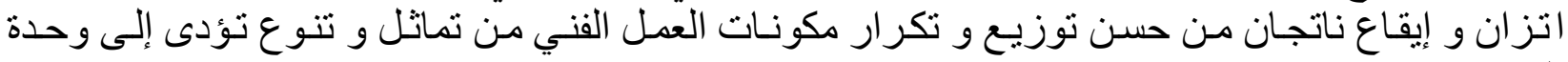

\section{و يمكن تناول الثبكات الهندسية من خلال جانبين أساسيين هما :}

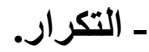

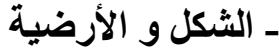

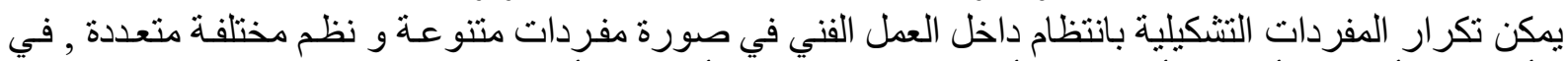

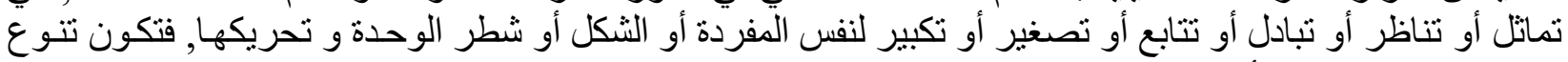

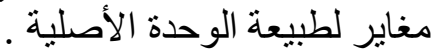

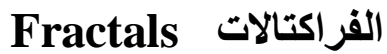

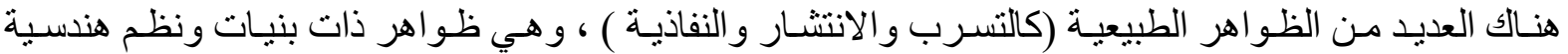

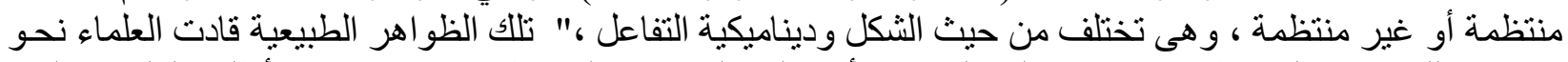

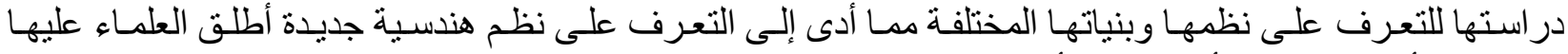

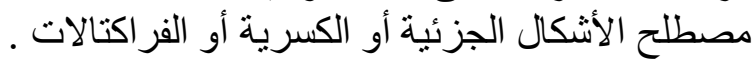

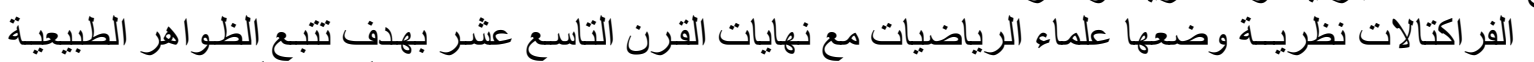

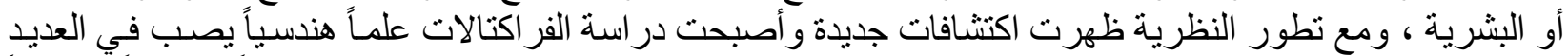

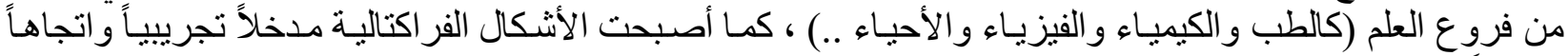

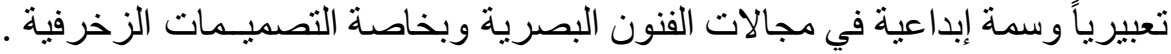
النظم الرياضية التكرارية الفر اكتالية : مجموعة ماندلبروت .مجموعة جوليا .مجموعة كانتور .مثلث

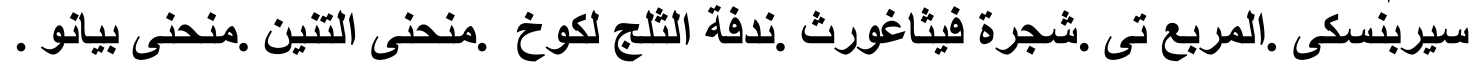

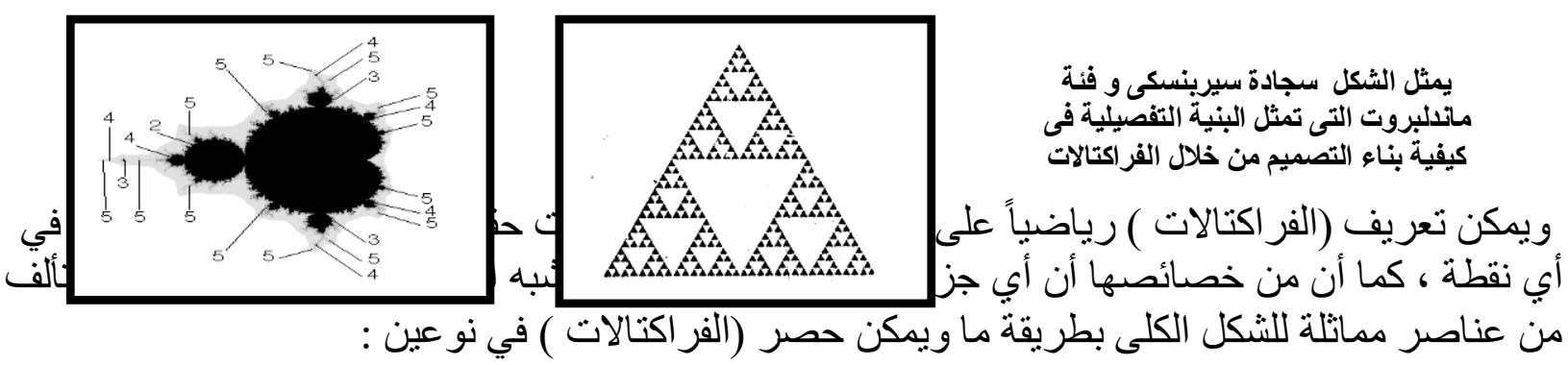

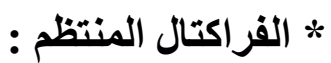

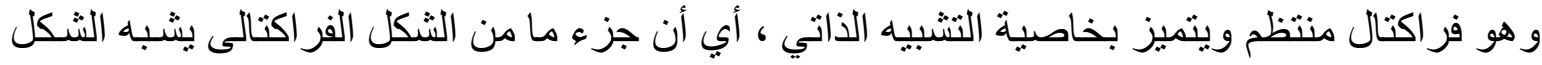

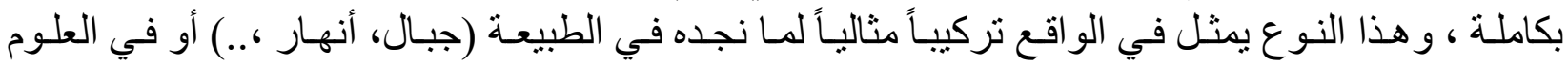

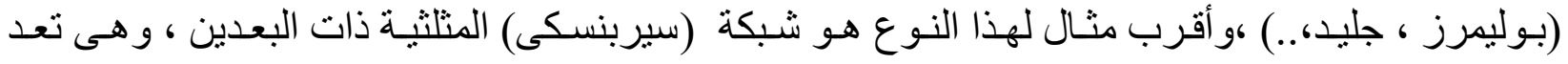


فر اكتالية محددة بشكل جيد ، حيث تبدأ بمثلث متساوي الأضلاع، ثم ثلاث مثلنات جنباً إلى جنب ، ثم تكرر العملية و هكذا ... - مالية

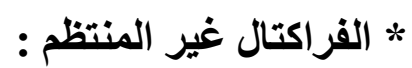

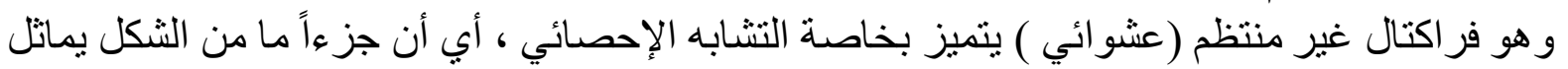

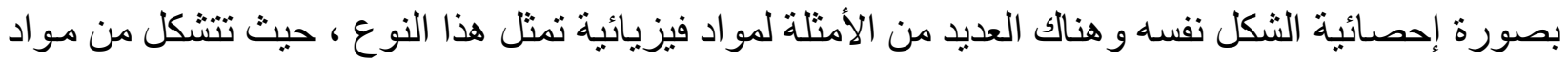

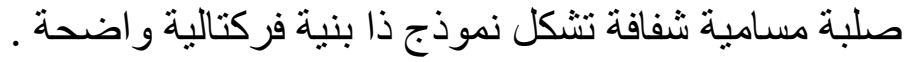

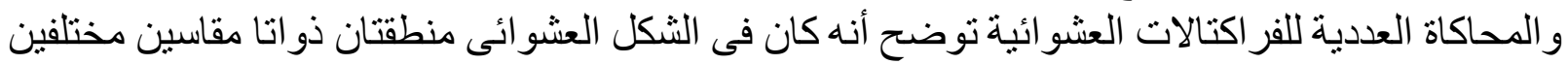

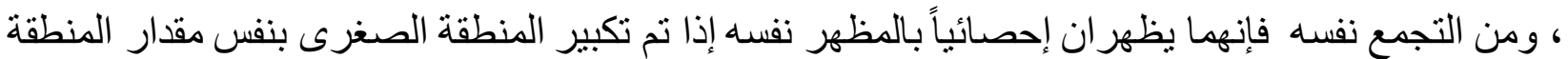

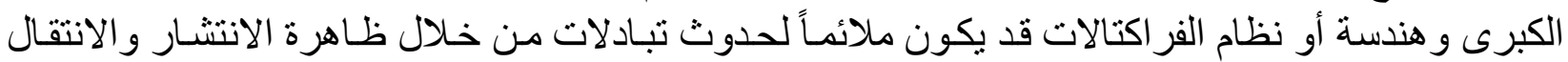

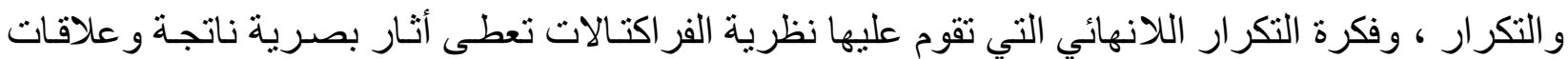

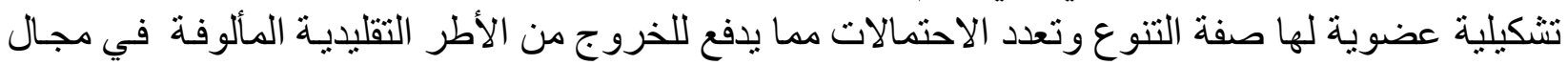

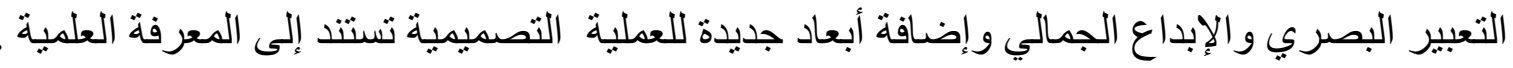

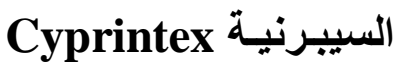

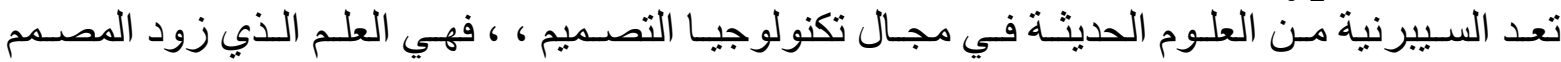

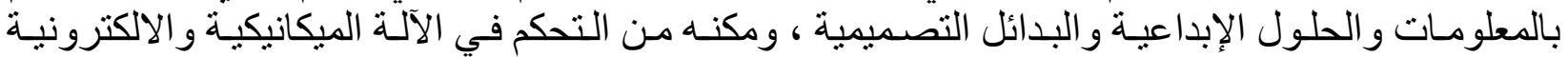

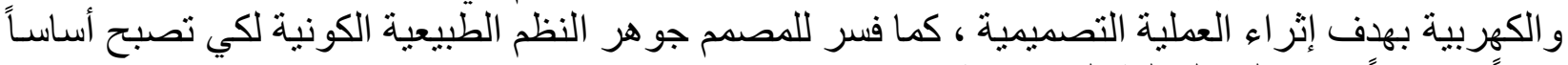
بنائياً و إنشائياً تقوم عليه العملية التصميمية .

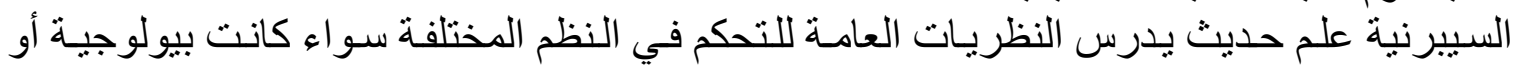

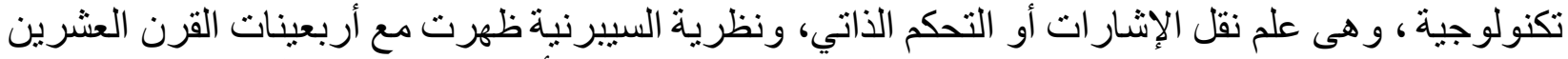

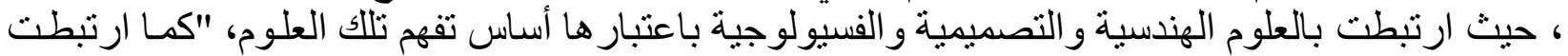

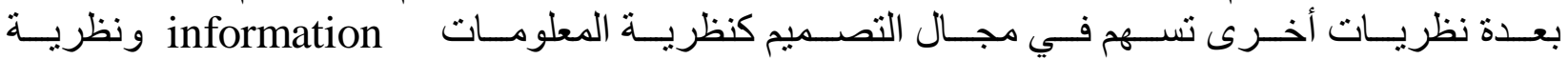
الالجوريثمAlgorithm ونظرية الاوتوماتية

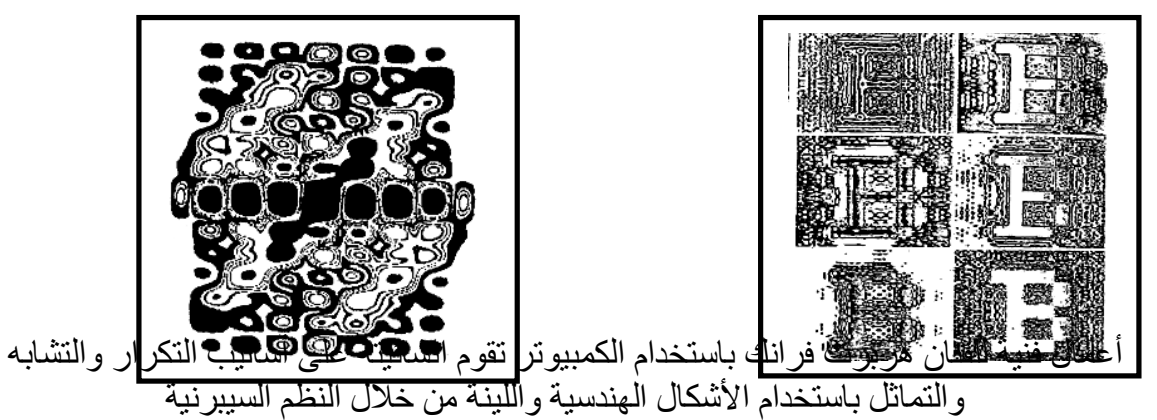

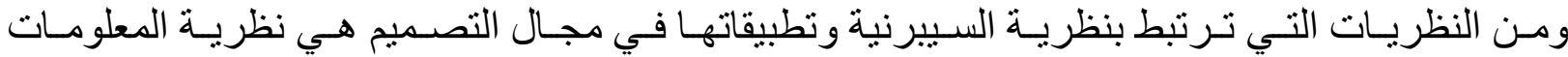

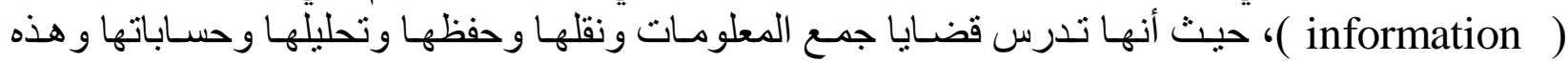

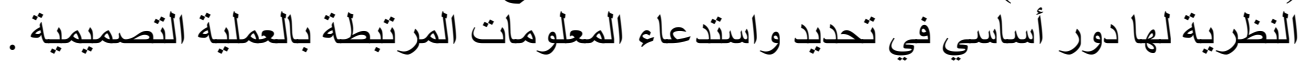

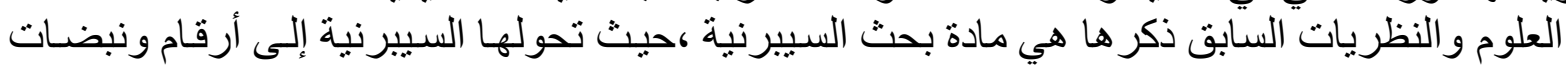

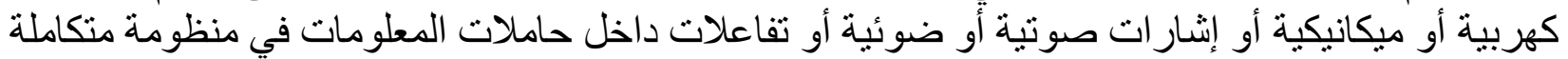

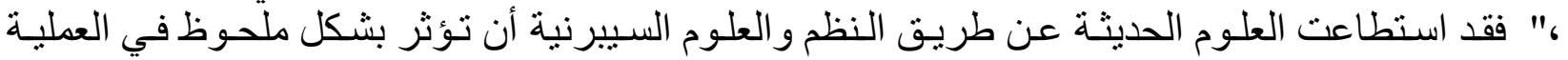



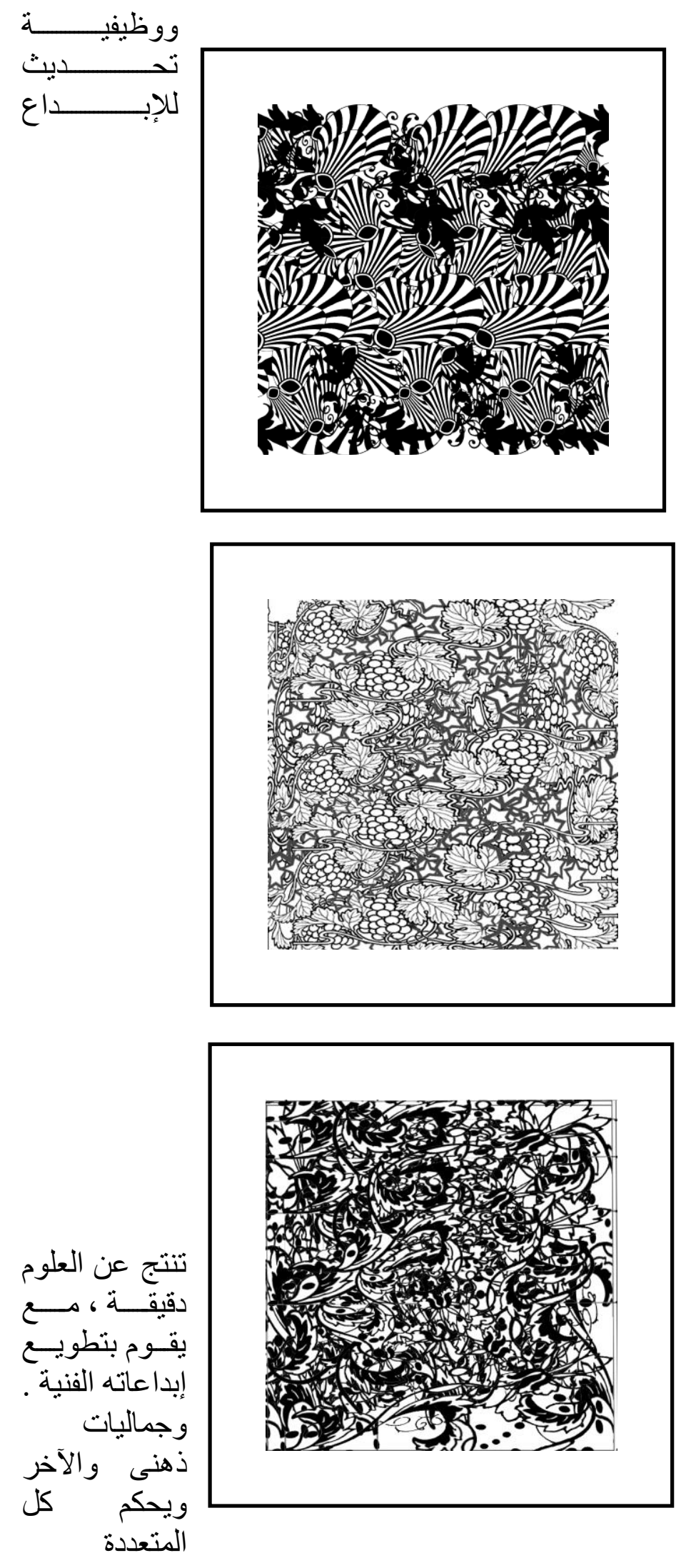

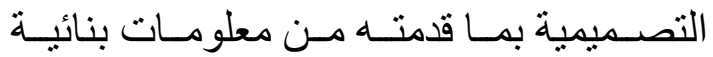
وبصرية و اقتصـادية كان لها دور اً مؤثراً في في النيا

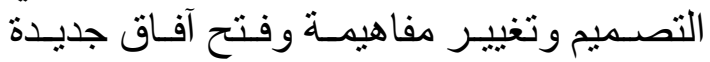

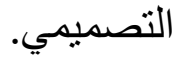

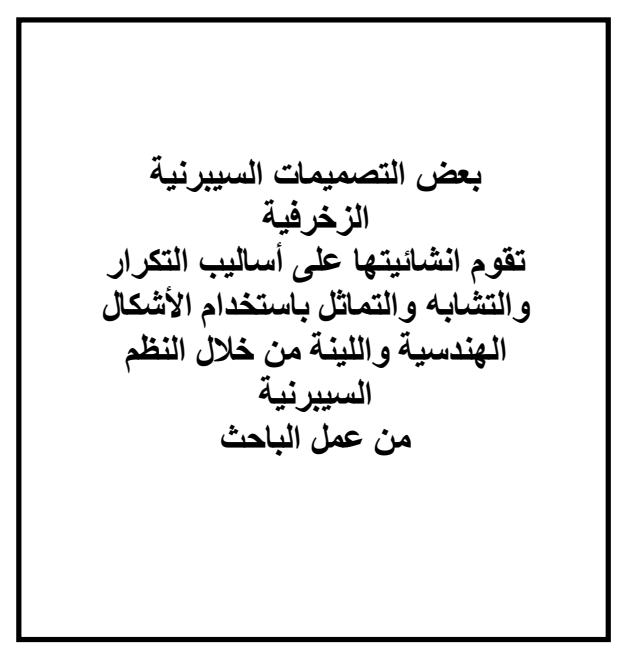

وبــالر غم مـن أن التصـميمات التـي

السيبرنية قد تتسم بالتعقيد إلا أنها ذات نتائج الأج

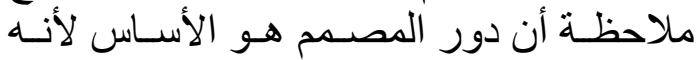

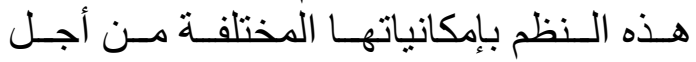
وقد استخلص الباحث أن بنائية

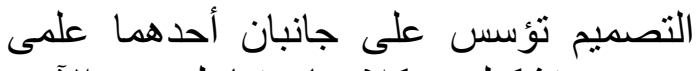
بصرى تشكيلى وكلاهما متفاعل مع البان الآخر

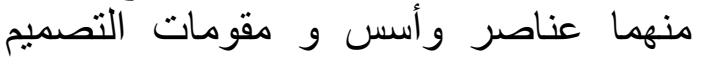


و العو امل المؤثرة فيه . - م.

\section{الحروف المقطعة في القرآن الكريم}

هي فو اتح السور التي تكون على شكل حروف هجائية مفردة أو شبه مفردة، وظهرت الحروف العزب المقطعة في

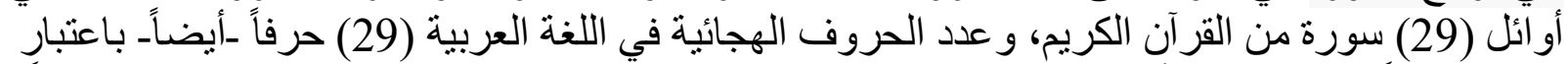

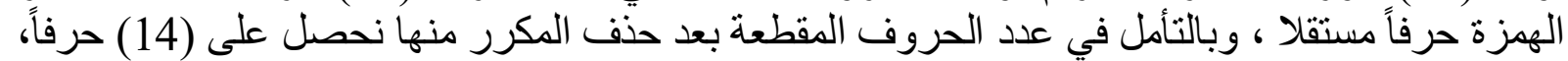

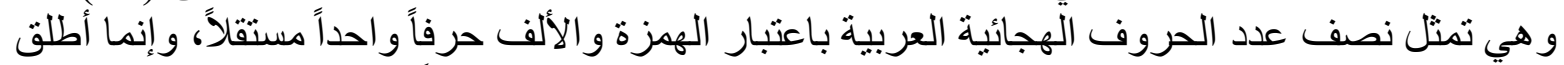

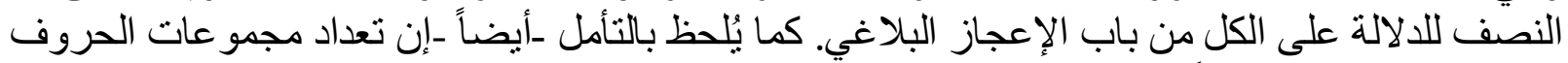
الدقطعة التي ذكرناها آنفاً (الم، الدص، الر، ، ...الخ (تمثل هي الأخرى (14) مجموعة حرفية الإنة

وتصنف الحروف المقطعة على أساس المباني إلى :

\begin{tabular}{|c|c|c|}
\hline القلٍ - قي - ص & 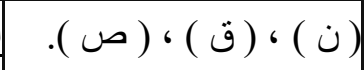 & 1 لحروف ذات الحرف الو احد و التىى لم تتكرر \\
\hline النمل - يس - طه & | (طس ) ، ( يس) ، ( طه ). & الحرفين والتى لم تتكرر \\
\hline غافر، فصلتي، الزخرف، الدخان، الجاثية، الأحقاف & (حم ). & 3 حروف ذات الحرفين والتى تكررت 7 مرات \\
\hline الثشعر /ءوالقصص & (طسم ) - (طس) & 4 حروف ذات الثلاث أحرف و التى تكررت مرتان \\
\hline البة انْ،العنكبوت، الروم،لقمان، السجدة: & (الم ). & 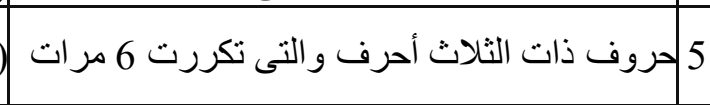 \\
\hline يونس، هوديويو سف، إبر اهيم، الحجر & 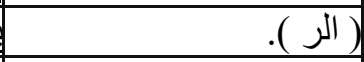 & 6 حروف ذات الثثلاث أحرف و التى تكررت 5 مر ات \\
\hline الر عد - الأعر اف & ( المر ) ، ( المص ). & 7 7حروف ذات أربعة أحرف ولم تتكرر \\
\hline ل مريم - الثنورى & ( كهيعص ) ( حمعقق) & 8 لحروف ذات الخس أحرف ولم تتكرر \\
\hline ن ح ق ن ) & ( & 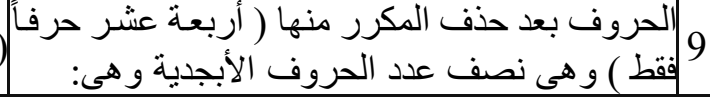 \\
\hline
\end{tabular}

السور التي تبدأ بتلك الحروف تحمل آية رقم (1) .

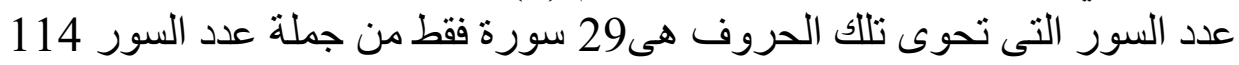

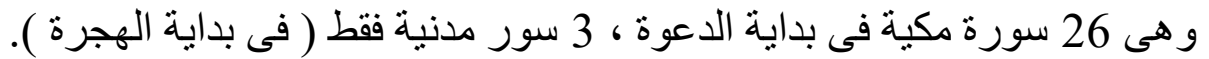

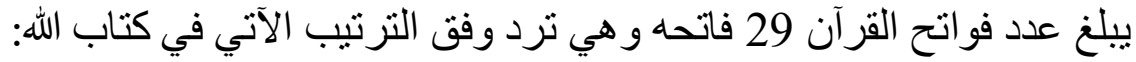

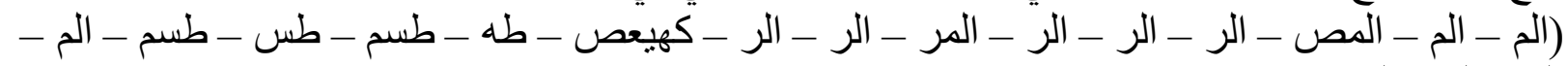

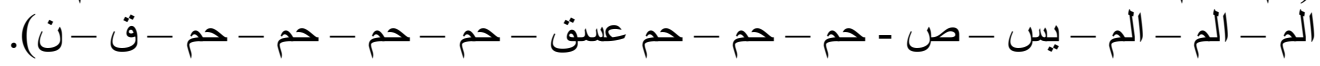

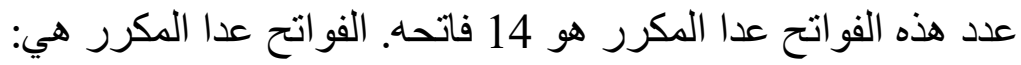

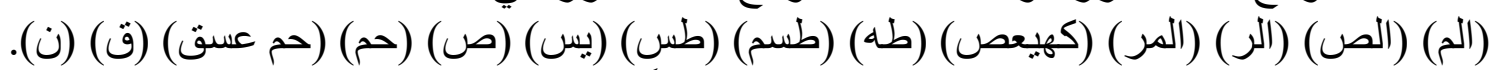

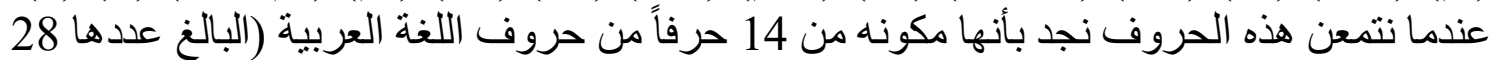

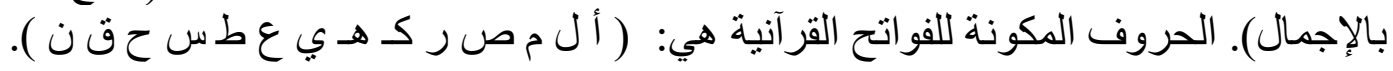

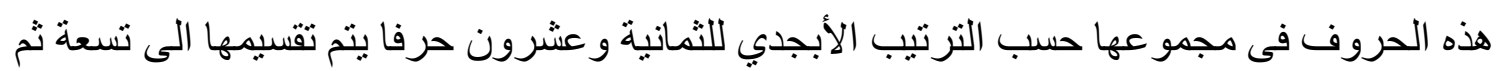

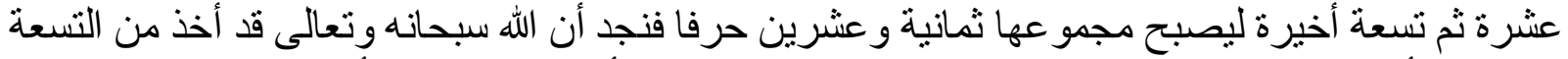

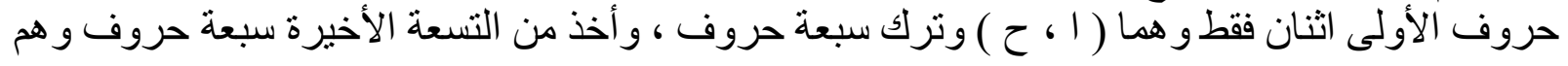


(ق ، ك ، م ، ن ، هـ ، ل ، ق ، ) ) وترك حرفان ، ومن العشرة حروف الوسطى أخذ الخمسة حروف الغير

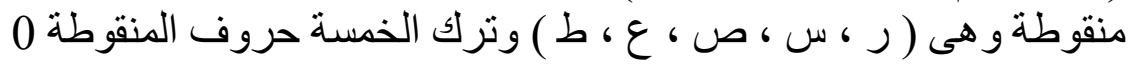

\section{- تطبيق الرموز على مستوى الآيات والسور}

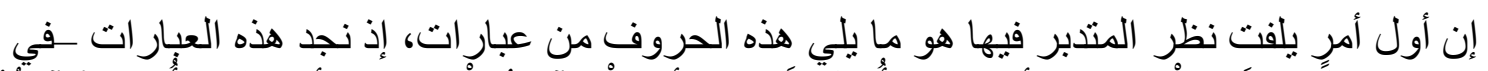

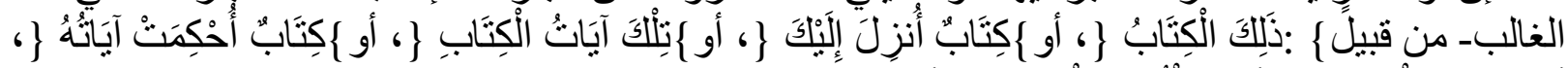

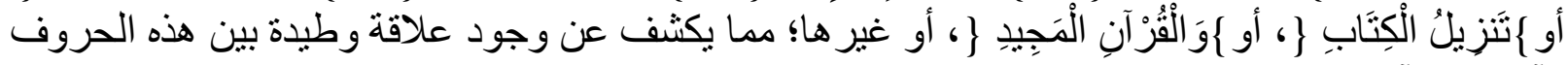

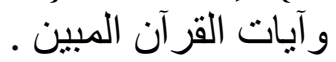

\section{- نظام الترقيم على حساب فواتح السور :}

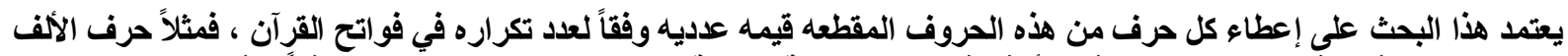

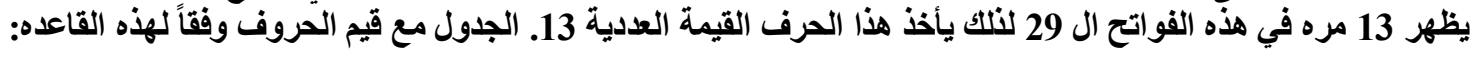

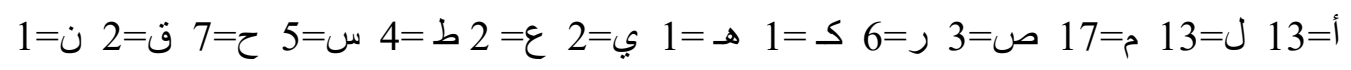

كل الحروف المقطعة تأخذ قيمه عدديه وفقاً لعدد تكر ارها بين الفو اتح إلا حرف الهاء فهو حاله استثنائية. لهذا الحرف قيمت فئان:

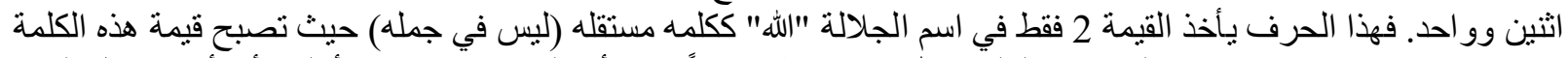

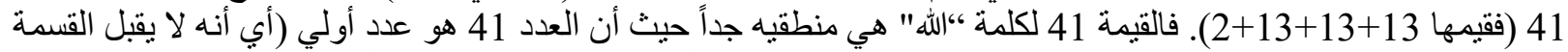

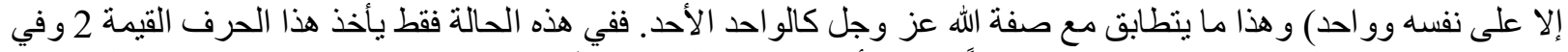

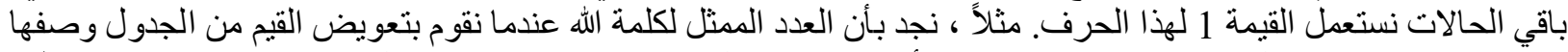
( العدد العالأ 1131313 ) يقبل القسمة على 41 لمرتين ( أب على مربع ال 41 ) ) ، و هذا ما يؤكد تمثيل العدد 41 لاسم الجلالة "الله". و الله أعلم..

بالنسبة للقيمة واحد لحرف الهاء (لكل الحالات إلا لمجموع قيم كلمة الله) فهي مثبته من خلال العديد من الظواهر في النص القرآني . ملاحظه : باقي الحروف في العربية (التي لا تظهر بين فواتح القرآن) تأخذ القيمة ( صفر ) .

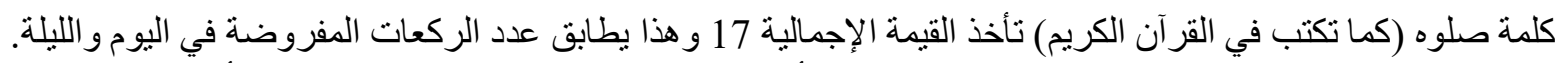

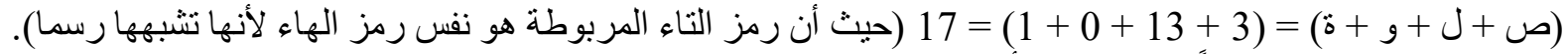

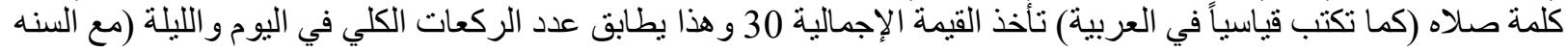

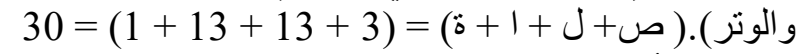
كلمة حج تأخذ القيمة الإجمالية 7 و هو (جد عدد مر ات ات الطو اف حول الكعبة، و وعدد مر ات السعي بين الصفاو المروة، وعدد الجمرات

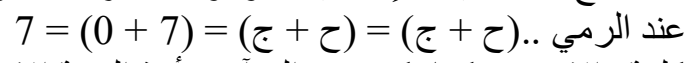

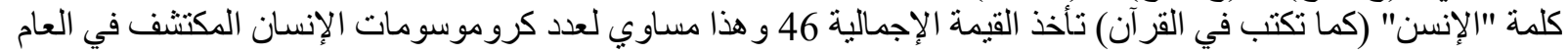

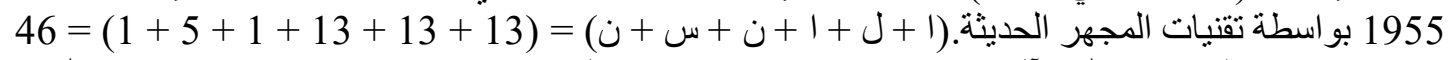

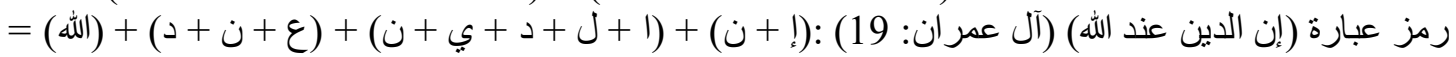
$87=41+3+29+14=(41)+(0+1+2)+(1+0+2+13+13)+(1+13)$

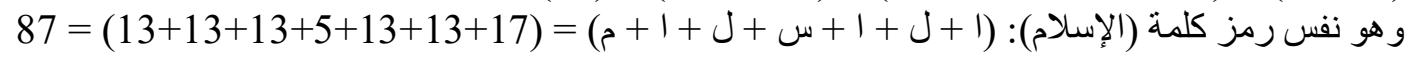

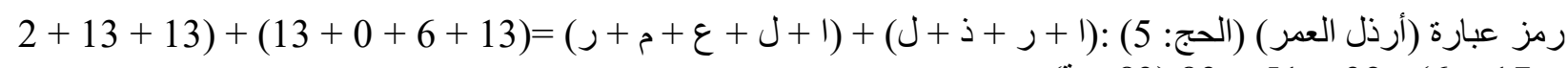

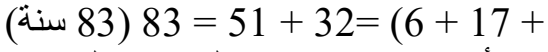
كما أن رمز عبارة (وقد بلغت من الكبر عتيا) (مريم: 8) 


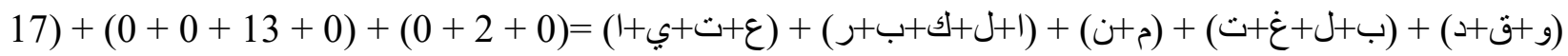
( 83) $83=17+33+18+13+2=(13+2+0+2)(6+0+1+13+13)+(1+$ كما أن رمز عبارة (إني و هن العظم مني) (مريم: 4) = 83 (83 سنة) هذه الآيات هي من خطاب سيدنا زكريا عليه السلام لله عز وجل.

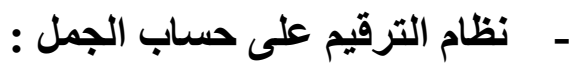

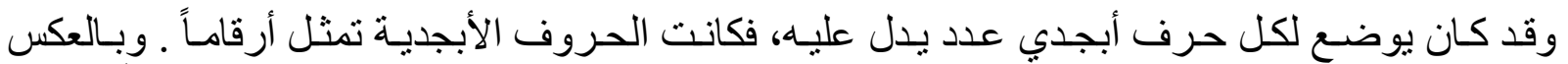

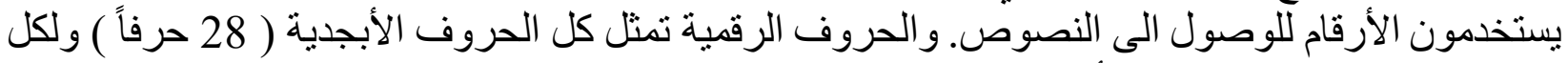
حرف له مدلوله الرقمي التي تبدأ برقم 1 ونتنتهي عند الرقم 1000 و هى كالآتي:

$$
\text { مفتاح الحروف الرقمية وترتيبها الأصلي القديم : }
$$

\begin{tabular}{|c|c|c|c|c|c|c|c|c|c|c|}
\hline ] & $b$ & $\tau$ & & s & $\rightarrow$ & & ج & ب & & الحروفت \\
\hline & 9 & 8 & 7 & 6 & 5 & 4 & 3 & 2 & 1 & أرقامها \\
\hline & ص & i & $\varepsilon$ & س & نان & ? & J & s) & ज & الحروف \\
\hline & | & 80 & 70 & 60 & 50 & $\overline{440}$ & 30 & 20 & 10 & أرقامها \\
\hline$\dot{\varepsilon}$ & b & ض & $\dot{j}$ & $\bar{\tau}$ & $\vec{\Delta}$ & 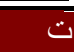 & ش & $\bar{J}$ & $\overline{3}$ & الحروف \\
\hline 1000 & $\overline{9900}$ & 8800 & $\overline{700}$ & $\overline{6600}$ & $\overline{500}$ & $\overline{400}$ & 300 & 200 & $\overline{100}$ & رقامها \\
\hline
\end{tabular}

\begin{tabular}{|c|c|c|c|c|}
\hline المدلول الثبكي & القيمة العددية & 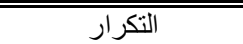 & الحروف & السورة السورة \\
\hline & $426=71 * 6$ & 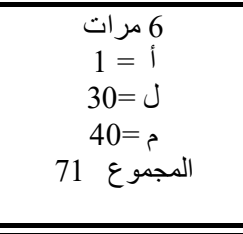 & 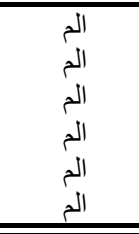 & 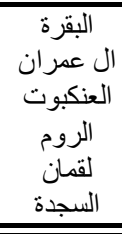 \\
\hline & $\overline{240}$ & 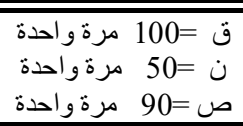 & ن ن & صاقلم \\
\hline & $\begin{array}{l}=109 * 2 \\
=18 \text { مرتان } 218\end{array}$ & 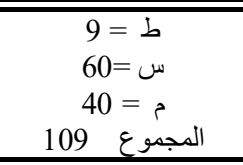 & طس طس & القصر الشعراء \\
\hline & 271 & مرة واحدة & 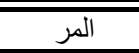 & الرعد الرع \\
\hline & 278 & مرةواحدة & حم*عقق & الثورى \\
\hline & 70 & مرة واحدة & بس بس & يس ليس \\
\hline & $\overline{69}$ & مرة واحدة & طس & النمل \\
\hline
\end{tabular}




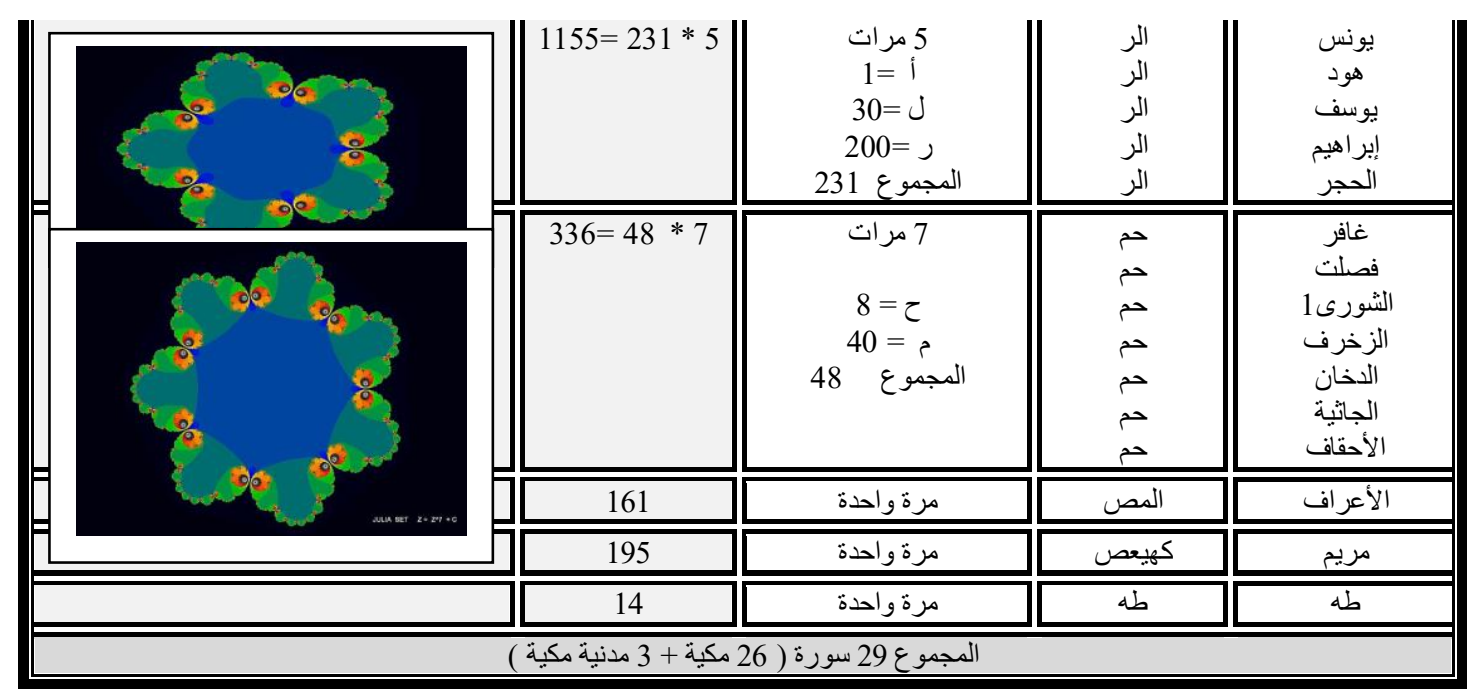

• بجمع عدد مرات التكرار (10+7+5+2+6 فردى) = 30 وهو يشير لعدد اجز اء القرآن الكريم • بتقسيم الحروف و باستخدام معادلات مجمو عات جوليا الفر اكتالية وتطبيقها على العدد المستتتج تنتج الاعمدال التصميمبة التالية :

$$
\text { المجموعة الاولى : أ = } 1 \text { ، ل = } 30 \text { ، م = } 40 \text { بمجموع بم }
$$

$$
\text { وحيث إنها مكررة } 6 \text { مرات فيكون الناتج هو } 626=71 \text { * }
$$

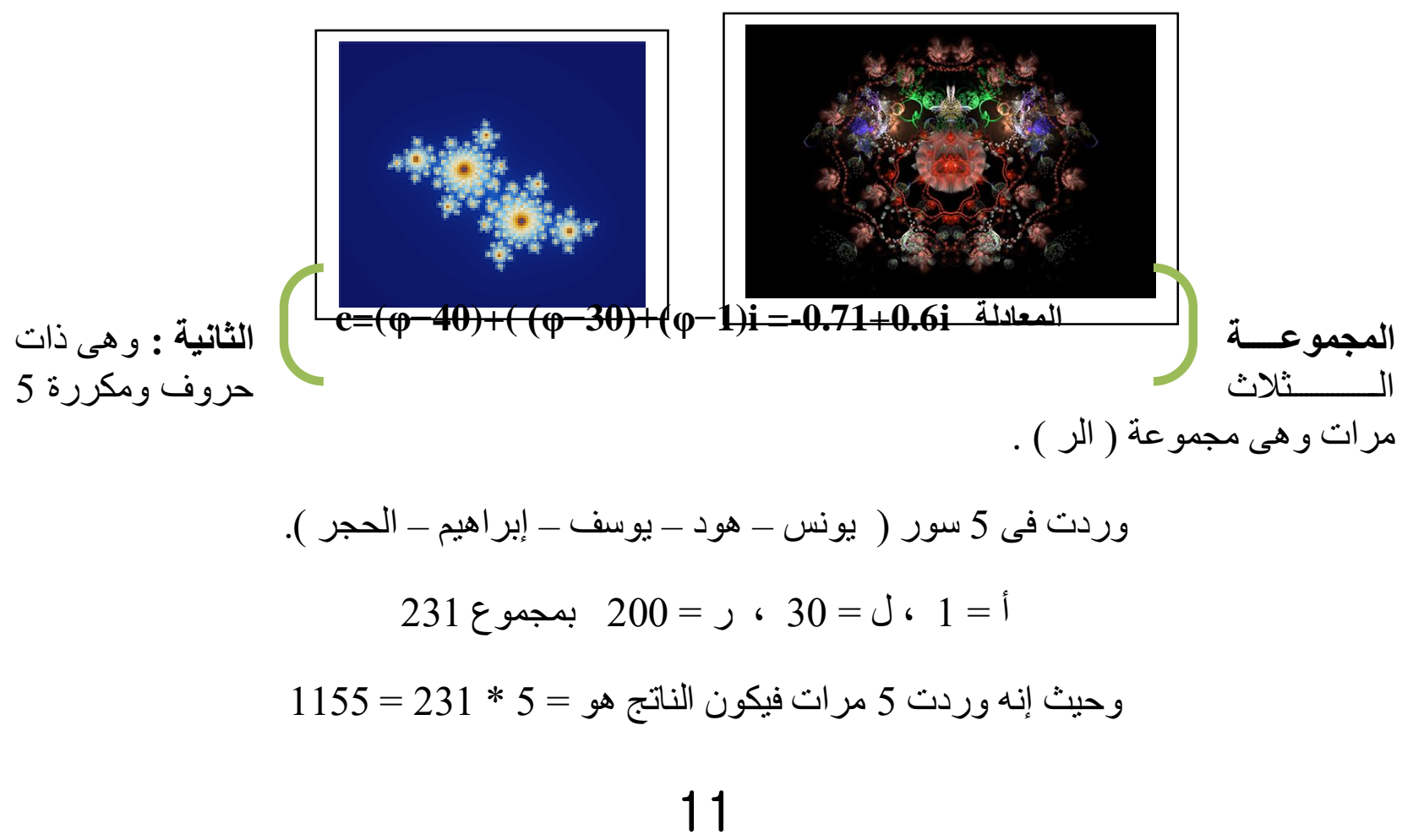




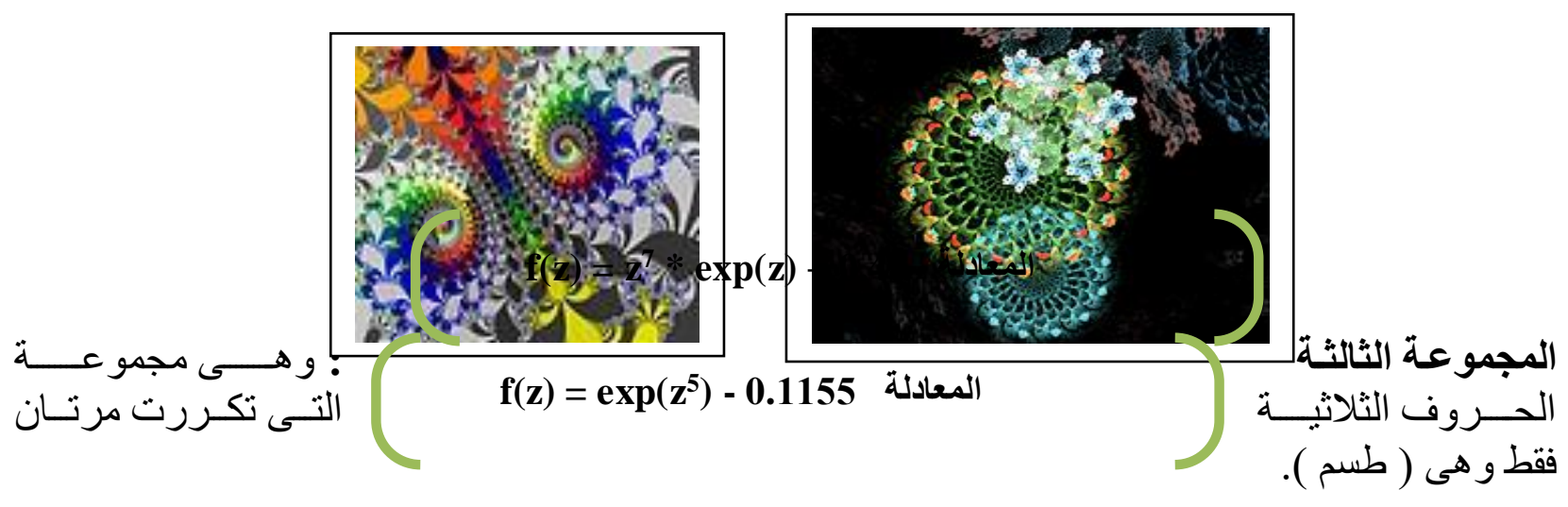

$$
\begin{aligned}
& \text { فى سورة ( الثعر اء ـ القصص ) } \\
& \text { ط= 9 ، س = } 60 \text { ، ، م= } 109 \text { فيكون المجموع } \\
& \text { وحيث أنها تكررت مرتان فيكون القيمة العددية =2 * } 218=109
\end{aligned}
$$
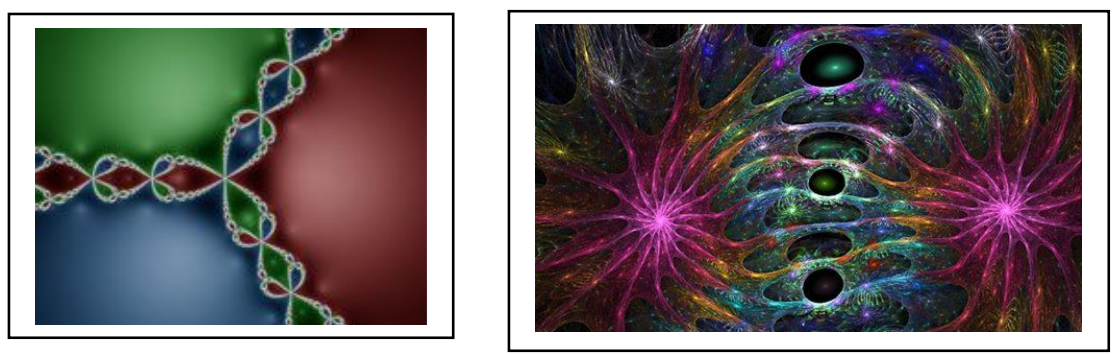

$$
\begin{aligned}
& \text { المجموعة الرابعة : وهى الحروف الثنائية والتي تكررت } 7 \text { مر ات فى } 7 \text { سور وهى ( حم ). }
\end{aligned}
$$

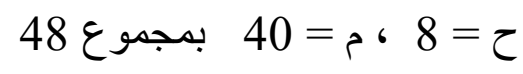

وحيث أنها تكررت 736 مرات فيكون مجموع الأعداد هى : 7 * 48
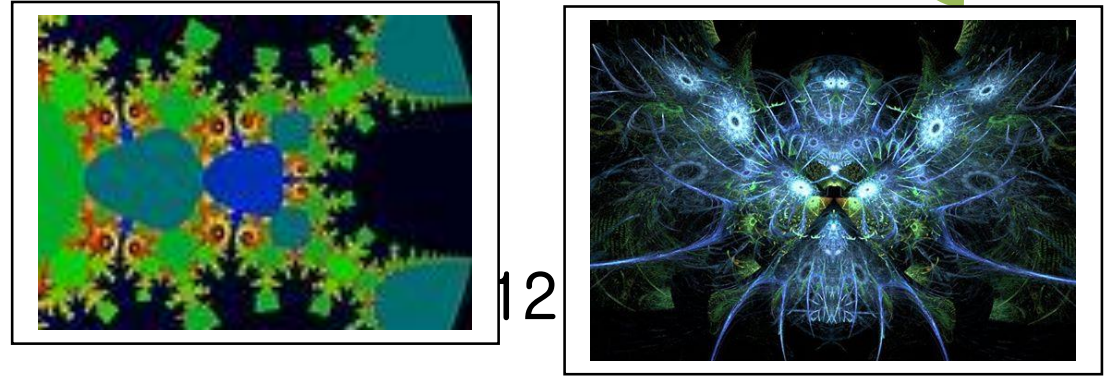


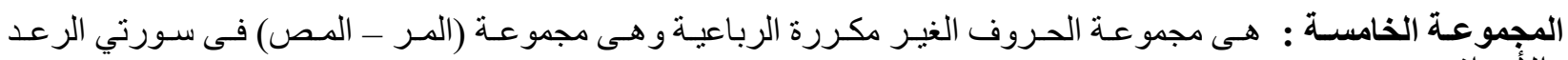

$$
\begin{aligned}
& \text { والأعراف }
\end{aligned}
$$

مجمو عة و احدة

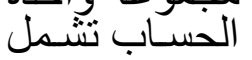

$$
f(z)=\left[\left(z^{2}+z\right) / \operatorname{Ln}(z)\right]+(0.70,0.69,0.14 i) \quad \text { المعادلة }
$$

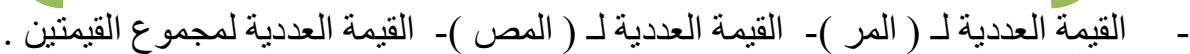

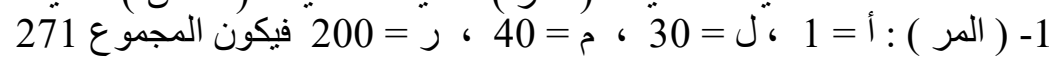

2 - ( المص ) : أ = 1 ،ل =30 ، م= 40 ، ص = 90 بمجموع 161

$$
\text { 3- مجموع القيمتين ( المر + الدص ) أى ( } 431 \text { + } 161 \text { ) ) }
$$
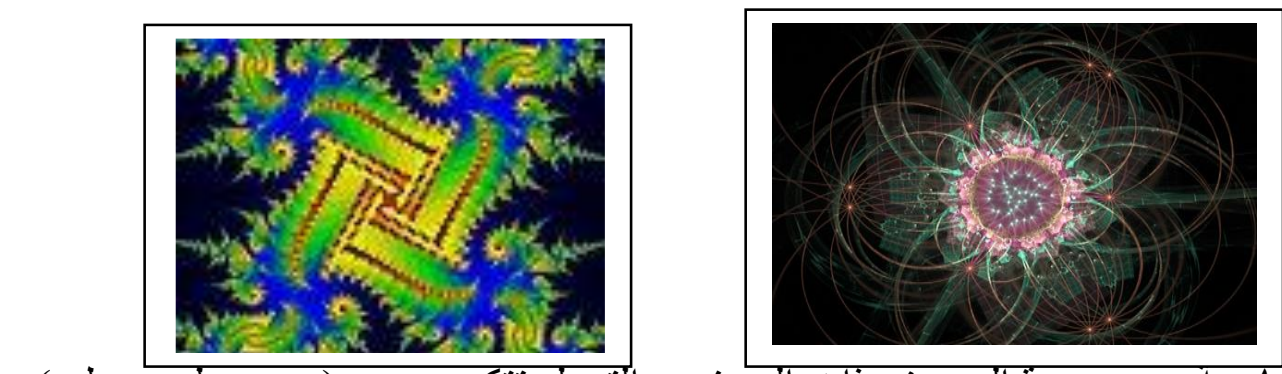

المجمو عة السادسه : مجمو عة الحروف ذات الحرفين و التى لم تتكرر وهى ( يس- طس - طه ).

1- و هى تعتبر مجمو عة واحدة : ( يس = 70 ، طس = 69 ، طه = 14 ) بجملة عددية = 153
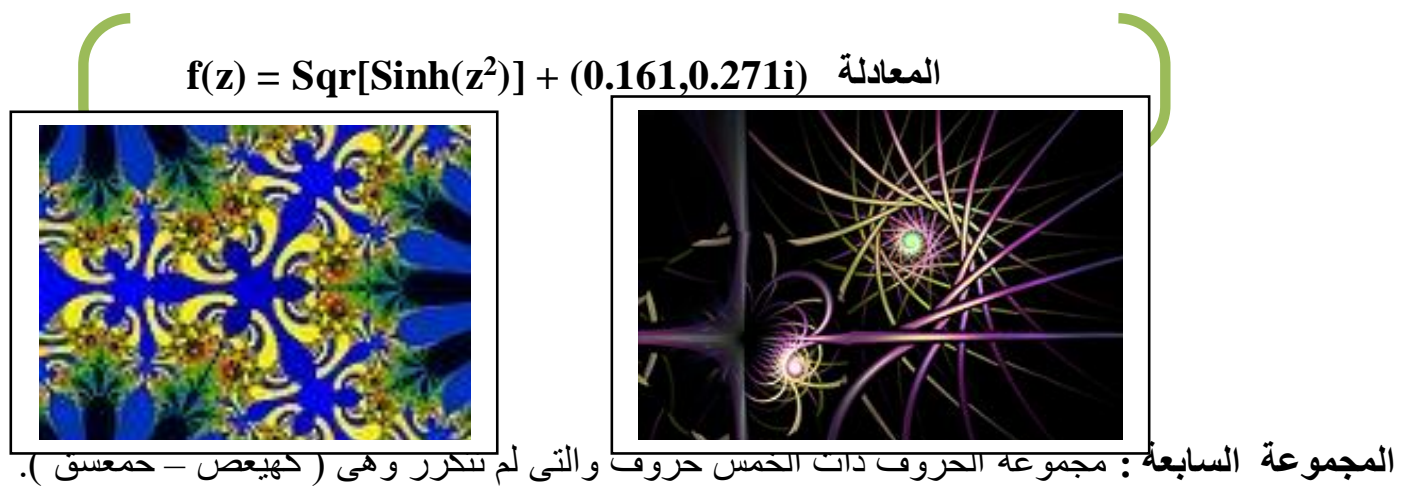

وحيث انهما من مجمو عة واحدة فيكون طريقة حسابها :

1- القيمة العددية لـ كهيعص. 2- القيمة العددية لـ حمعسق. 3- مجموع القيمتين. 


$$
\text { ( كهيعص ) : وردت مرة واحدة فى سورة مريم : }
$$

ك = 20 ، هـ = 5 ، ي = 10 ، ع = 70 ، ص = 90 فيكون المجموع 195

فـــــورة

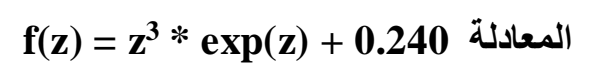

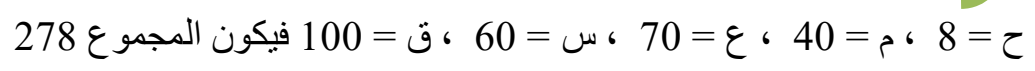

مجموع القيمتين السابقتين لنفس المجمو عة الخماسية ( كهيعص + حمعقق ) :

$$
473=(\text { S } 278 \text { (كيعص 195+ حمعسق })
$$
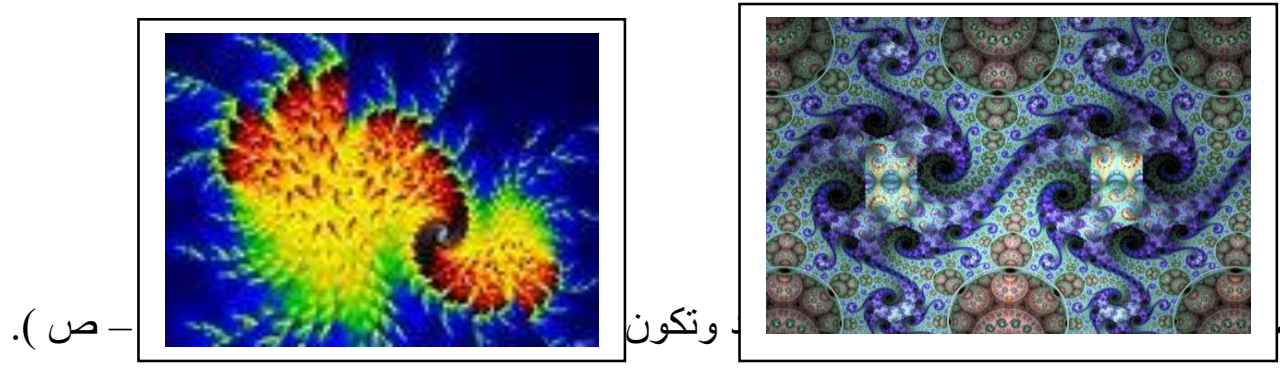

المجموعة الثام

$$
\text { ( ق =100 ، ن = 50 ، ص = } 90 \text { وجملة أرقامها = } 240 \text { ). }
$$
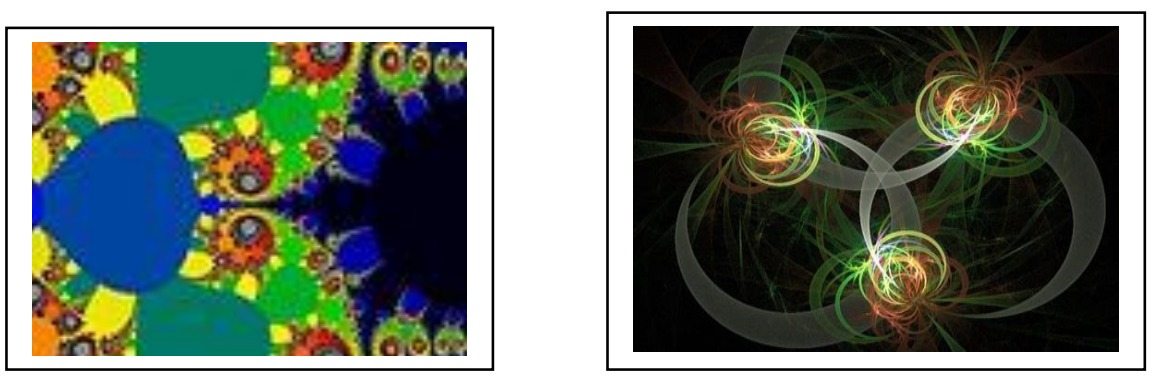

التاســعة: فـى حالــة

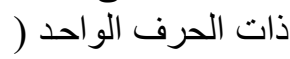

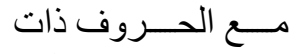

$f(z)=\left[\left(z^{2}+z\right) / \operatorname{Ln}(z)\right]+(0.195,0.278 i)$

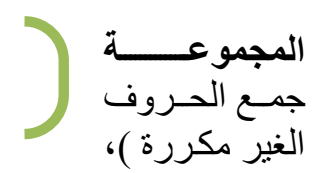

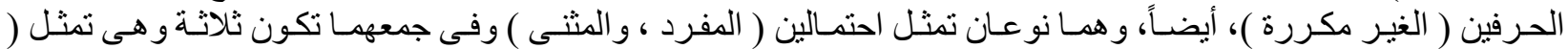

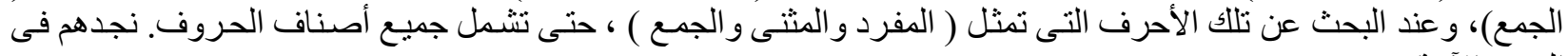
السور الآتية : البعان

1- سورة ق ، سورة ص ، سورة القلم (ق +ص + ن = 240 ). الكفرد الغير مكرر .

2- سورة طه ، سورة يس ، سورة النمل ( طه+ يس+ طس= 153). المثنى الغير مكرر. 

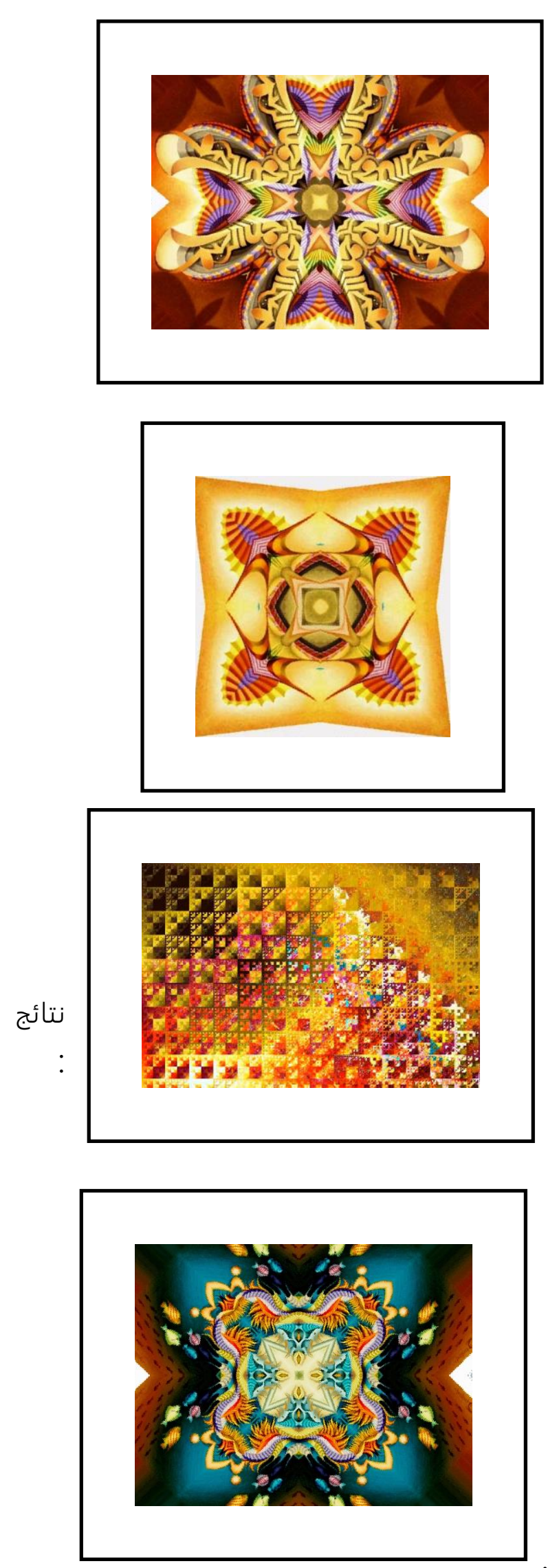
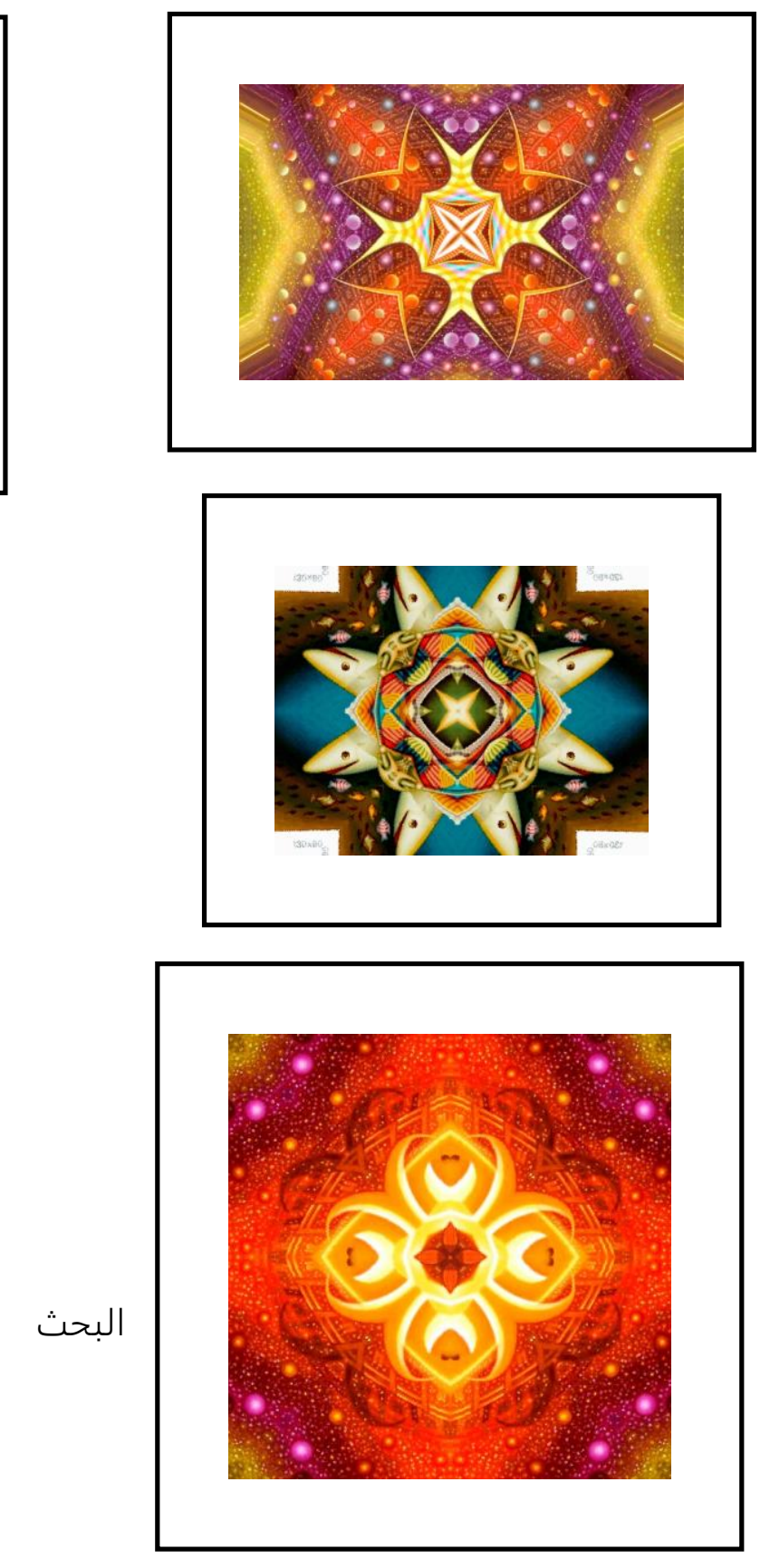

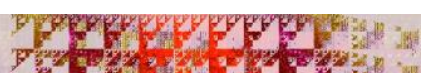

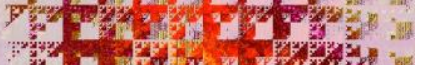
y $13 \times 2, y$

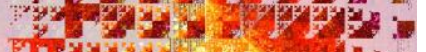

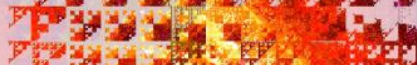
Fy Fy

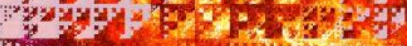
Jin 
1- ان دراسة وتحليل العلاقات الجمالية والنظم الرياضية في الطبيعة يساعد على فهم وتكشف الكثير من النظم التصميمية والبنائية الكامنة في المظاهر الاخلية والخارجية لمفردات الطبيعة التثكيلية ويعمل ذلك على اثراء

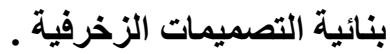

2- البعد الانشائي الجمالى للتصميمات الزخرفية يمكن من خلاله توظيف العلاقات الرياضية للخطوط بتنوع انماطها

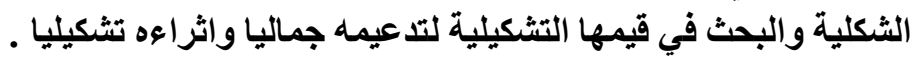

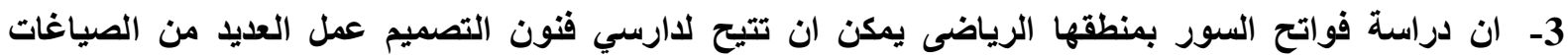

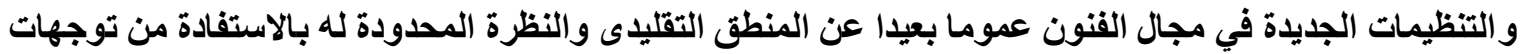

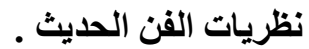

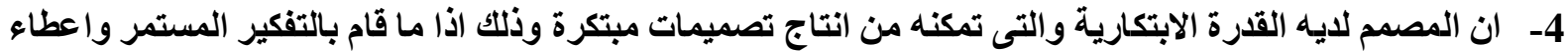

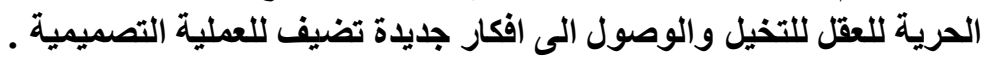

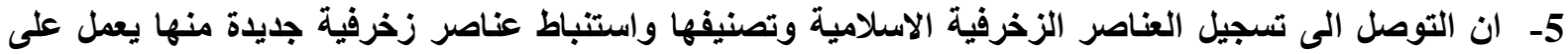

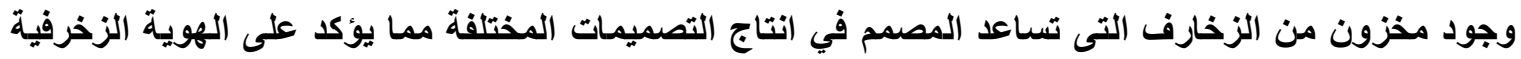

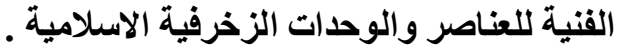

التوصيات :

1- الاهتمام بمنطقة التجريب في تعليم الفن وذلك لمحاولة الكثف عن النظم البنائية الكامنة وراء مفهوم علاقة الثكل بالصياغة والطبيعة . 2- اهمية دراسة وتحليل العلاقات الثكلية الجمالية والنظم الرياضية التصميمية في الطبيعة لما لها من اهمية كتمهيد

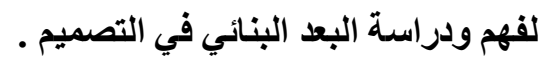
3- تلريب الطالب على مهارات التفكير الابداعى في تكوين تثكيلات زخرفية واستحداث تثكيلات مبتكرة حتى يتعود

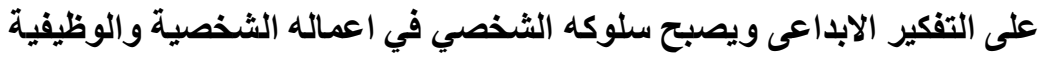

المراجع

2.

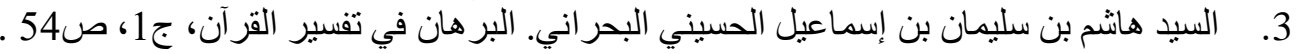

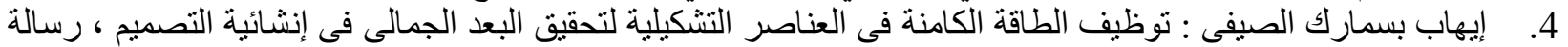

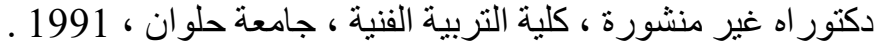

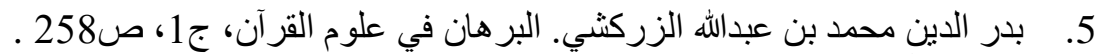

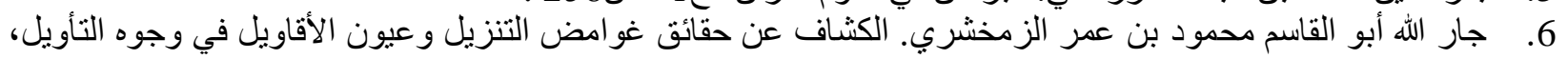
7. عادل عبد الرحمن أحمد: نظرية الفر اكتالز بين البعد العلمى و المنظور الإبداعي، بحث منشور ، مجلة بحوث في التربية

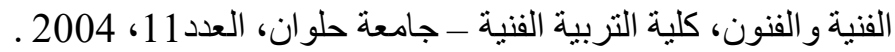

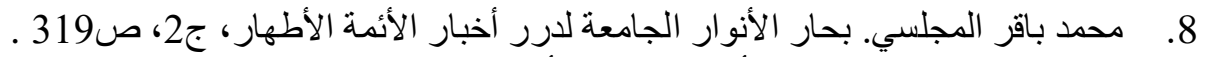

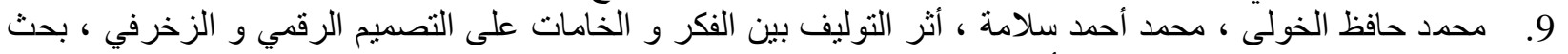

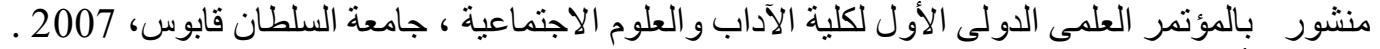

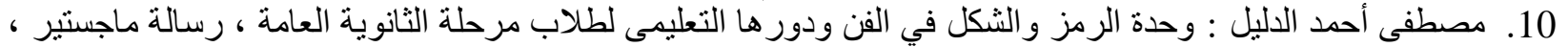

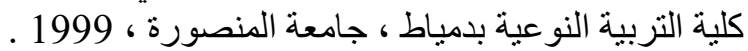




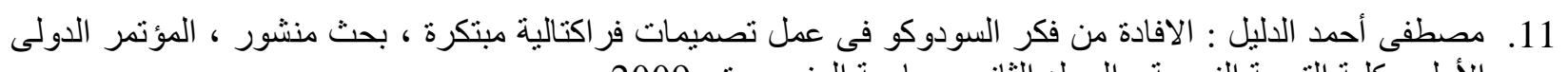

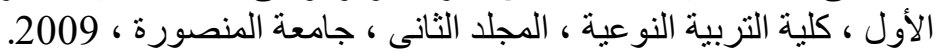

12. Fractals and Chaos, An Illustrated Course ,Institute of Physics (IoP) Publishing, 1997.

13. Addison, Paul S : Fractal design, Congress, QD139, 2000.

14. Diffusion, Cambridge University, New Yourk, 1999.

15. Brumfiel,,Charles: Mathematical ideas, harber Collins, New York,1993.

16. Daniel Ben - Avraham : Disordered systems and reactions in fractals and Parmanand, Singh: The So-called Fibonacci numbers in ancient and medieval India, Historia Mathematica, 1985.

17. www. wikipedia.org/wiki/Julia_se

18. www.fotosearch.com

19. www.islsmicart.org

20. www.mathacademy.com

21. www.mathworld.wolfram.com

22. www.superstock.com

23. www.wikipedia.org 